\title{
Among-individual diet variation within a lake trout ecotype: Lack of stability of niche use
}

\author{
Louise Chavarie ${ }^{1,2,3}$ (D) | Kimberly L. Howland ${ }^{4,5}$ | Les N. Harris ${ }^{4}$ | Colin P. Gallagher ${ }^{4}$ | \\ Michael J. Hansen ${ }^{6}$ | William M. Tonn ${ }^{5}$ | Andrew M. Muir ${ }^{7}$ | Charles C. Krueger ${ }^{3}$
}

${ }^{1}$ Faculty of Environmental Sciences and Natural Resource Management, Norwegian University of Life Sciences, Ås, Norway

${ }^{2}$ Scottish Centre for Ecology and the Natural Environment, IBAHCM, Glasgow, UK

${ }^{3}$ Department of Fisheries and Wildlife, Center for Systems Integration and Sustainability, Michigan State University, East Lansing, MI, USA

${ }^{4}$ Fisheries and Oceans Canada, Winnipeg, $\mathrm{MB}$, Canada

${ }^{5}$ Department of Biological Sciences, University of Alberta, Edmonton, AB, Canada

${ }^{6}$ U.S. Geological Survey (retired), Hammond Bay Biological Station, Millersburg, MI, USA

${ }^{7}$ Great Lakes Fishery Commission, Ann Arbor, MI, USA

\section{Correspondence}

Louise Chavarie, Faculty of Environmental Sciences and Natural Resource

Management, Norwegian University of Life

Sciences, Ås, Norway.

Email: chavarie@ualberta.ca

Funding information

Funds are from Fisheries and Oceans Canada (DFO), Northern Development Canada Northwest Territories Cumulative Impacts Monitoring Program grants, Polar Continental Shelf Program, Sahtu Renewable Resource Board, and the Great Lakes Fishery Commission. Funding bodies had no role in the study design, in the collection, analysis and interpretation of data, in writing the manuscript or the decision to submit the paper for publication.

\begin{abstract}
In a polyphenic species, differences in resource use are expected among ecotypes, and homogeneity in resource use is expected within an ecotype. Yet, using a broad resource spectrum has been identified as a strategy for fishes living in unproductive northern environments, where food is patchily distributed and ephemeral. We investigated whether specialization of trophic resources by individuals occurred within the generalist piscivore ecotype of lake trout from Great Bear Lake, Canada, reflective of a form of diversity. Four distinct dietary patterns of resource use within this lake trout ecotype were detected from fatty acid composition, with some variation linked to spatial patterns within Great Bear Lake. Feeding habits of different groups within the ecotype were not associated with detectable morphological or genetic differentiation, suggesting that behavioral plasticity caused the trophic differences. A low level of genetic differentiation was detected between exceptionally large-sized individuals and other piscivore individuals. We demonstrated that individual trophic specialization can occur within an ecotype inhabiting a geologically young system (8,000-10,000 yr BP), a lake that sustains high levels of phenotypic diversity of lake trout overall. The characterization of niche use among individuals, as done in this study, is necessary to understand the role that individual variation can play at the beginning of differentiation processes.
\end{abstract}

\section{KEYWORDS}

Arctic, fatty acids, generalist, genetic, morphology, resource use, Salvelinus namaycush, specialist 


\section{1 | INTRODUCTION}

Phenotypic diversity within fish species that have colonized postglacial lakes often represents early stages of species diversification (Snorrason \& Skúlason, 2004). Many fishes that have colonized postglacial freshwater systems are assumed to have been plastic generalists (i.e., flexible in use of habitat and food resources) at the time of colonization (Skúlason et al., 2019; Snorrason \& Skúlason, 2004). Given the novel environment and new ecological opportunities, a newly established population may begin to display among-individual differences in behavior and other phenotypic characteristics (Skúlason et al., 2019). Phenotypic plasticity, the capacity for one genotype to produce different phenotypes in response to environmental cues, could be a character subject to selection, facilitating the process of diversification (De Jong, 2005). Despite uncertainties of how phenotypic plasticity promotes divergence, plasticity appears to serve as an important element in early phases of diversification (Handelsman et al., 2013; Nonaka et al., 2015; Snorrason \& Skúlason, 2004). Theory predicts that recently colonized systems with multiple stable and predictable habitats and resources would favor foraging and habitat specialization and increase the probability of eco-morphological diversification (Skúlason et al., 1999; Snorrason \& Skúlason, 2004; Van Kleunen \& Fischer, 2005).

Phenotypic plasticity in temporally and spatially variable environments has been demonstrated repeatedly within and among populations (Skúlason et al., 2019). Whether niche expansion of a population is achieved by a general increase in niche widths for all individuals overall or by an increase of among-individual variation (i.e., expression of multiple individual specializations within a population) is a question in ecology that remains unanswered (Bolnick et al., 2003; Roughgarden, 1972; Svanbäck \& Schluter, 2012). Several apparent generalist populations have been reported to be composed of combinations of specialized individuals using several narrow niches that together yield an overall wide population niche (Araújo et al., 2008, 2011; Bolnick et al., 2003). Postglacial lakes and co-inhabiting species offer a wide range of characteristics that may favor or constrain individual specialization. Postglacial lakes are depauperate ecosystems with low interspecific competition (Snorrason \& Skúlason, 2004), which provides ecological opportunities that likely favor niche expansion (Bolnick et al., 2010; Costa et al., 2008; Parent et al., 2014). Additionally, the large flexibility within postglacial colonizing species, with individuals having the potential to exploit a wide range of resources, can facilitate the evolution of individual resource specialization and population divergence. Yet, northern ecosystem food webs are subject to strong seasonal and episodic influences of climate and the environment (McMeans et al., 2015). Accordingly, using a broad resource spectrum has been identified as a useful strategy for fishes living in Arctic environments, where food can be patchily distributed and ephemerally available. Understanding the magnitude and effect of individual specialization in species and trophic positions is necessary to appreciate the role that variation among individuals can play at the beginning of differentiation processes (Cloyed \& Eason, 2016; De León et al., 2012; Svanbäck et al., 2015.

Great Bear Lake (Northwest Territories, Canada), spanning the Arctic Circle, provides an excellent opportunity to investigate the role of among-individual diet variation in diversification processes in postglacial lakes (Figure 1). Here, lake trout, Salvelinus namaycush, show a high degree of intraspecific diversity within a geologically young system (8,000-10,000 yr BP; Johnson, 1975; Pielou, 2008). Specifically, extensive sympatric divergence has occurred for this species with four ecotypes inhabiting the shallow-water $(\leq 30 \mathrm{~m})$ zone of Great Bear Lake (Figure S1; Chavarie, Harford, et al., 2016; Chavarie et al., 2013, 2015; Harris et al., 2015). Three of these four shallow-water lake trout ecotypes are described as trophic generalists with differing degrees of omnivory along a weak benthic-pelagic gradient (Chavarie, Harford, et al., 2016; Chavarie, Howland, Gallagher, et al., 2016). Despite habitat and dietary overlap, significant differences in morphological, genetic, and life-history variation have been reported (Chavarie et al., 2013; Chavarie, Howland, Venturelli, et al., 2016; Harris et al., 2015). The suggested resource use of the three ecotypes could be caused by the combination of individual specialists along a resource continuum (Chavarie, Howland, Gallagher, et al., 2016). In other words, although ecotype resource use may appear similar, individuals within an ecotype may differ in their resource use. One of these three generalist ecotypes (Ecotype 2; generalist with a tendency to consume more fish than other ecotypes, referred here as the piscivorous ecotype; Figure 2) showed at least two different feeding strategies, benthic cannibalism and interspecific piscivory in the pelagic zone (Chavarie, Howland, Venturelli, et al., 2016).

To characterize niche use and individual variation within an ecotype in relation to observed differentiation of feeding strategies, we focused this study solely on of the piscivorous lake trout ecotype and its fatty acid profiles. Fatty acid analysis assumes that dietary lipids are broken down into their constituent fatty acids and incorporated relatively unchanged into consumer tissues (Howell et al., 2003; Iverson, 2009; Iverson et al., 2004), allowing spatial and temporal diet comparison among individuals (Duerksen et al., 2014; Eloranta et al., 2011; Hoffmann, 2017; Iverson, 2009; Scharnweber et al., 2016). Although internal regulation of fatty acids or biosynthesis is possible (Chaguaceda et al., 2020; Keva et al., 2019; Ruess \& Müller-Navarra, 2019), fatty acids have been assessed to be a robust tool to characterize lake trout diets (Happel et al., 2016, 2017). Thus, fatty acids were used as trophic bio-indicators to better understand dietary patterns of piscivorous lake trout and investigate whether variation occurred among individuals in this ecotype and if individual specialization may be contributing to trophic patterns of this ecotype. Specifically, our aims were to (a) compare resource use among lake trout individuals within Ecotype 2 (piscivores) by characterizing their fatty acid profiles, (b) determine whether resource-use differences were influenced by life-history traits (e.g., size and age), (c) characterize and compare morphological variation among groups that expressed different feeding strategies, and (d) determine if genetic differences existed among groups. Because frequently an 
FIGURE 1 Map of Great Bear Lake, Northwest Territories, Canada, adapted from Johnson (1975), indicating general bathymetry, the terrestrial ecozones (i.e., geographical region having a distinct biodiversity of flora and fauna) adjacent to the lake, and major inflowing and outflowing rivers. Insert: location of study area within Canada

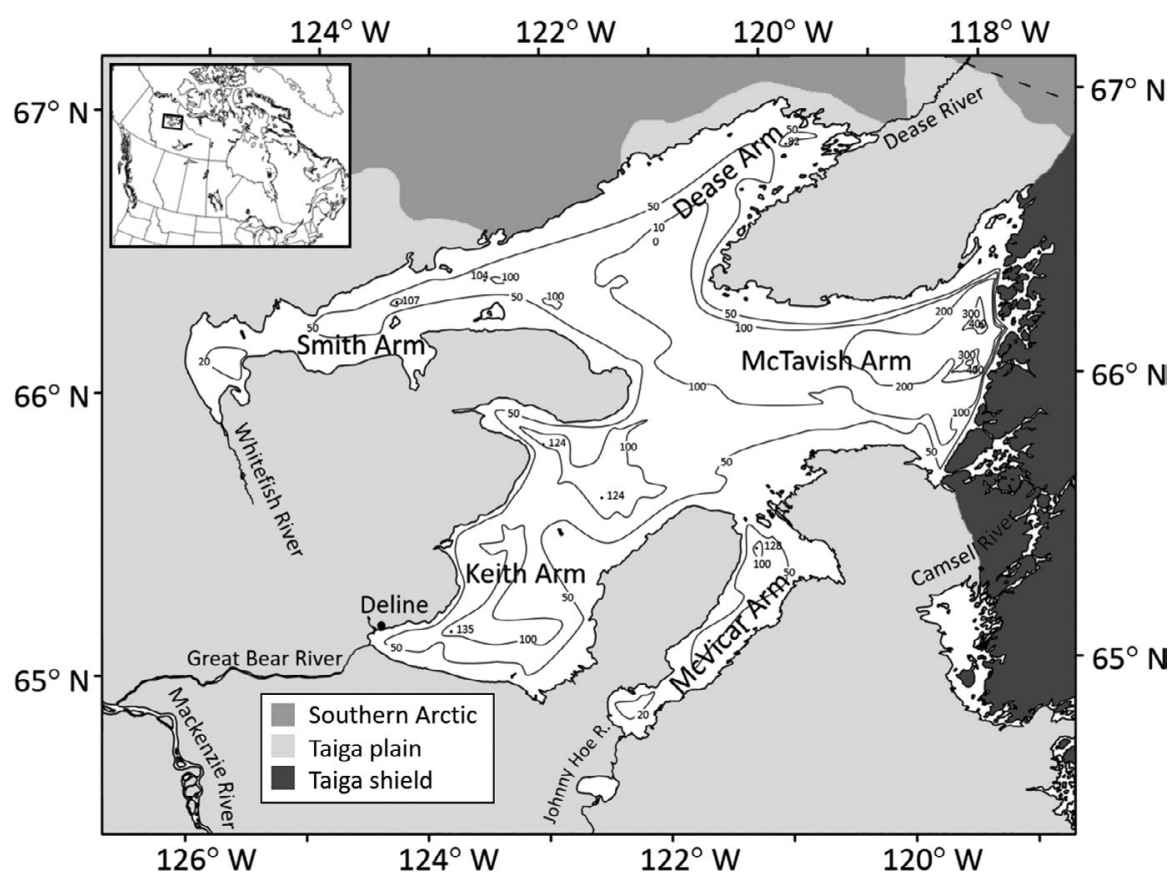

association can be made between body size and niche use (Werner $\&$ Gilliam, 1984), we examined a subset of the largest lake trout of this ecotype from our collections ( $\geq 900 \mathrm{~mm}$ in fork length) referred to locally as "Giants" (Figure 2). The aim by including the Giants in our analysis was to determine whether they showed any ecological and genetic differences from others of this ecotype based on their remarkable and unusual size. These exceptionally large individuals of $900 \mathrm{~mm}$ comprise $<1 \%$ of the lake trout population sampled in Great Bear Lake and are among the largest lake trout in the world (Chavarie, Howland, Venturelli, et al., 2016). Except for their singular large body size, these individuals show no major morphological or spatial and temporal distribution differences relative to other co-occurring piscivorous lake trout.

\section{2 | METHODS}

\section{1 | Study area and field sampling}

Great Bear Lake is an oligotrophic Arctic freshwater system, $250 \mathrm{~km}$ south of the Arctic Ocean, in Northwest Territories, Canada (N66 $06^{\prime} \mathrm{W} 120^{\circ} 35^{\prime}$ ) (Johnson, 1975). As the world's ninth largest and 19th deepest lake, the lake has a complex, multi-armed surface area of $31,790 \mathrm{~km}^{2}$ and a maximum depth of $446 \mathrm{~m}$ (mean depth $=90 \mathrm{~m}$ ). Great Bear Lake was formed by scouring from the Laurentide icesheet during the Pleistocene and was originally part of glacial Lake McConnell 8,000-10,000 yr BP (Johnson, 1975; Pielou, 2008). The lake has characteristics typical of an arctic lake: ultra-oligotrophic, short ice-free season, and a simple food web supporting only 15 fish species (Alfonso, 2004; Johnson, 1975; MacDonald et al., 2004). Great Bear Lake lacks a commercial fishery but plays an important role in the local economy, supporting a fly-in sport fishery for tourists and a subsistence fishery for the small Sahtu community of Déline. Great Bear Lake has considerable intraspecific diversity within lake trout, lake whitefish (Coregonus clupeaformis), and cisco (C. artedi) (Chavarie et al., 2013; Howland et al., 2013).

Piscivorous lake trout were caught at depths $\leq 30 \mathrm{~m}$ using paired bottom sets (ca. $24 \mathrm{hr}$ ) of 140-mm and multi-mesh (38$140 \mathrm{~mm}$ ) stretched-mesh gill nets from late-July through August over multiple years (2002-2011) among all five arms of the lake (Table S1; Chavarie, Howland, Gallagher, et al., 2016; Chavarie et al., 2013, 2015). To increase the number of fish used in the Giant subset sample, we added lake trout caught during 20122014, from multi-mesh gill nets (38-140 mm), with a typical soak time of $24 \mathrm{hr}$, that were distributed across random depth-stratified sites (0-150 m) among Keith, McVicar, and McTavish arms (Giant only; Table S1, Figure 1). Compared to the other ecotypes, piscivores have a streamlined body, large gape, and high growth rates throughout life (Chavarie et al., 2013; Chavarie, Howland, Venturelli, et al., 2016. The piscivorous ecotype also displayed a modest level of genetic differentiation from the three other ecotypes (Harris et al., 2015).

We focused on adult trout due to the difficulty of classifying juveniles into ecotypes (Chavarie et al., 2013; Zimmerman et al., 2006, 2007) and to avoid the confounding effects of ontogenetic shifts in morphology, body size, and diet. Of 79 fish analyzed herein, 35 piscivourous lake trout (Ecotype 2) were previously analyzed for fatty acids by Chavarie, Howland, Gallagher, et al. (2016) and 44 fish were new additions to the diet analyses presented here. Fish were selected from collections analyzed morphologically by Chavarie et al. (2015) to include a range of sizes and ages within the piscivorous ecotype. For analyses involving giant individuals, we selected lake trout with fork lengths $\geq 900 \mathrm{~mm}$ which comprise the largest lake trout inhabiting Great Bear Lake. 

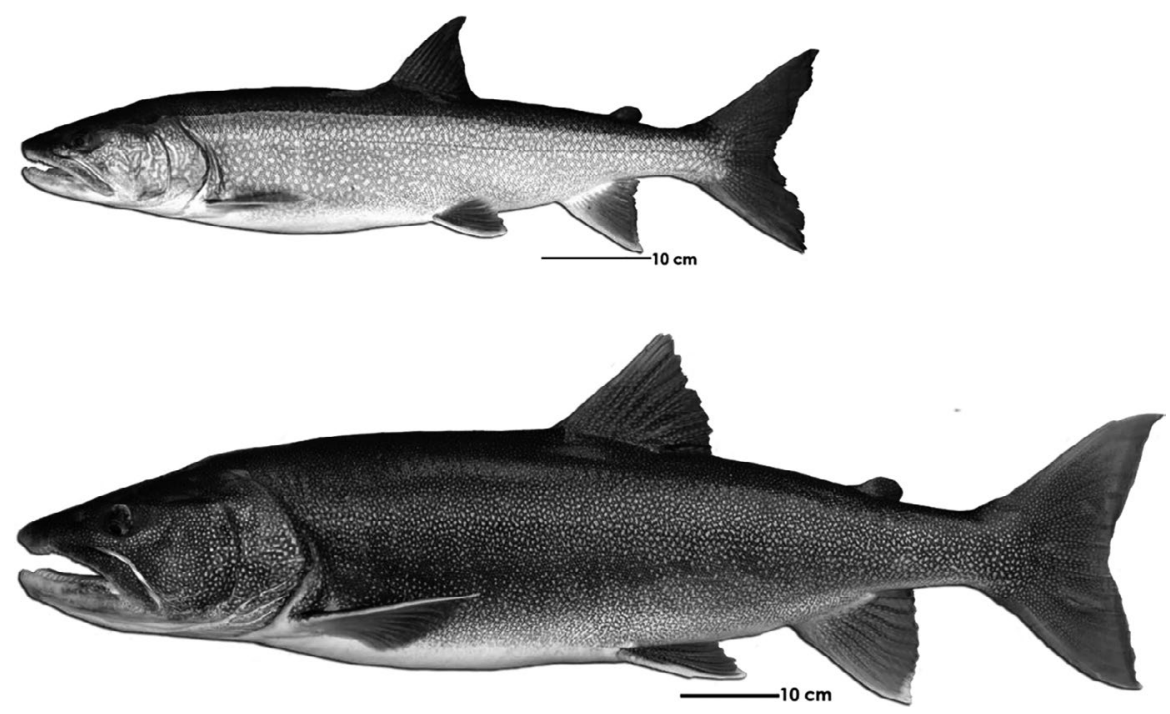

FIGURE 2 Example of a piscivorous $(64 \mathrm{~cm})$ and a Giant $(100 \mathrm{~cm}$ standard length) Lake Trout, respectively, from Great Bear Lake (NT)
A left lateral full-body digital image was taken for each lake trout caught according to the procedures described in Muir et al. (2012). Measurements, tissues, and structures were sampled to determine biological characteristics related to life-history, including otoliths (for age), fork length (for size), sex, and stage of maturity (i.e., immature, current year spawner, or resting) (Chavarie et al., 2013; Chavarie, Howland, Venturelli, et al., 2016). A dorsal muscle sample was collected and frozen at $-20^{\circ} \mathrm{C}$ for fatty acid analysis (Budge et al., 2006; Kavanagh et al., 2010; Loseto et al., 2009), and tissue from pectoral fins was collected and preserved in $95 \%$ ethanol for genetic analyses.

\subsection{Fatty acids}

Analysis of 41 dietary fatty acids was carried out using procedures described by Chavarie, Howland, Gallagher, et al. (2016) (Table 1). Muscle samples were freeze-dried and subsequently homogenized with a mortar and pestle. Lipids were extracted overnight from $1 \mathrm{~g}$ of homogenate in a 2:1 chloroform-methanol solution containing $0.01 \%$ $\mathrm{BHT}(\mathrm{v} / \mathrm{v} / \mathrm{w})$ at $-20^{\circ} \mathrm{C}$ (Folch et al., 1957). After extraction, samples were filtered through Whatman Grade 1 Qualitative filter paper and the filter paper/sample was rinsed twice with $2 \mathrm{ml}$ of the 2:1 chloroform:methanol. Sample extract was collected in a test tube, and $7 \mathrm{ml}$ of $0.88 \mathrm{~N} \mathrm{NaCl}$ solution was added to encourage fatty acids to move into the organic (chloroform) layer. The aqueous layer was discarded after which the chloroform was dried with sodium sulfate prior to total lipid measurement. The extracted lipid was used to prepare fatty acid methyl esters (FAME) by transesterification with Hilditch reagent (0.5 $\mathrm{N} \mathrm{H}_{2} \mathrm{SO}_{4}$ in methanol) (Morrison \& Smith, 1964). Samples were heated for $1 \mathrm{hr}$ at $100^{\circ} \mathrm{C}$. Gas chromatographic (GC) analysis was performed on an Agilent Technologies $7890 \mathrm{~N}$ GC equipped with a $30 \mathrm{~m}$ J\&W DB-23 column (0.25 mm I.D; $0.15 \mu \mathrm{m}$ film thickness). The GC was coupled to a Flame lonization Detector operating at $350^{\circ} \mathrm{C}$. Hydrogen was used as carrier gas flowing at $1.25 \mathrm{ml} / \mathrm{min}$ for $14 \mathrm{~min}$ and increased to $2.5 \mathrm{ml} / \mathrm{min}$ for $5 \mathrm{~min}$. The split/splitless injector was heated to $260^{\circ} \mathrm{C}$ and run in splitless mode. The oven program was as follows: $60^{\circ} \mathrm{C}$ for $0.66 \mathrm{~min}$, increasing by $22.82^{\circ} \mathrm{C} / \mathrm{min}$ to $165^{\circ} \mathrm{C}$ with a $1.97 \mathrm{~min}$ hold; increasing by $4.56^{\circ} \mathrm{C} / \mathrm{min}$ to $174^{\circ} \mathrm{C}$ and by $7.61^{\circ} \mathrm{C} /$ min to $200^{\circ} \mathrm{C}$ with a six min hold. Peak areas were quantified using Agilent Technologies ChemStation software. Fatty acid standards were obtained from Supelco (37 component FAME mix) and Nuchek (54 component mix GLC-463).

All fatty acid values were converted to a mass percentage of the total array and were named according the IUPAC nomenclature as $X: Y n-z$, where $X$ is the number of carbon atoms in the fatty acids, $Y$ is the number of methylene-interrupted double bonds in the chain, and $n-z$ denotes the position of the last double bond relative to the methyl terminus (Ronconi et al., 2010). Fatty acids suggested by Iverson et al. (2004) as important dietary fatty acids, which transfer from prey to predator, were used in our analyses (Table 1). Fatty acid profiles (\% of fatty acids) were transformed using arcsin square-root function. Fatty acid groups were identified using a multivariate analysis R Package (Team, 2017), FactoMineR, using a hierarchical clustering analysis based on principal components (Husson et al., 2012). To reduce the number of variables used, A SIMPER (similarity percentage routine) was performed using PAST 3 (Hammer et al., 2001) to assess which fatty acids were primarily responsible for observed differences among groups (King \& Jackson, 1999). A principal component analysis (PCA) was performed on the fatty acid profiles with PC-ORD version 6 (McCune \& Mefford, 2011) among piscivorous groups to provide inferences about patterns of resource use as defined by Chavarie, Howland, Gallagher, et al. (2016). Two-way permutational multivariate analysis of variance (PERMANOVA), a nonparametric analog of multivariate analysis of variance (MANOVA), was used to test for differences in fatty acid composition among the groups identified by FactoMineR and among arms of the lake (i.e., to investigate any spatial variations within the piscivorous ecotype). Two-way PERMANOVA was performed in PAST 3 using 9,999 permutations. Pairwise post hoc comparison (Bonferroni corrected) followed to test differences among groups defined by 
TABLE 1 Relative fatty acid concentrations of 41 fatty acids for the four groups of piscivorous Lake Trout morph identified from Great Bear Lake

\begin{tabular}{|c|c|c|c|c|}
\hline Fatty acids & Group 1 & Group 2 & Group 3 & Group 4 \\
\hline $14: 0$ & $6.8 \pm 1.0$ & $7.0 \pm 1.0$ & $9.2 \pm 1.0$ & $9.9 \pm 1.1$ \\
\hline $16: 0$ & $28.1 \pm 1.0$ & $28.13 \pm 1.7$ & $24.2 \pm 1.7$ & $26.1 \pm 1.2$ \\
\hline $16: 1 n-7$ & $15.9 \pm 3.7$ & $10.1 \pm 2.0$ & $19.5 \pm 3.4$ & $15.6 \pm 2.1$ \\
\hline $16: 2 n-6$ & $2.0 \pm 0.5$ & $2.4 \pm 0.6$ & $2.6 \pm 0.2$ & $3.1 \pm 0.2$ \\
\hline $16: 2 n-4$ & $2.6 \pm 0.7$ & $1.5 \pm 0.4$ & $2.7 \pm 0.9$ & $2.3 \pm 0.4$ \\
\hline $17: 0$ & $2.7 \pm 0.5$ & $2.8 \pm 0.3$ & $2.4 \pm 0.4$ & $2.8 \pm 0.2$ \\
\hline $16: 3 n-4$ & $1.5 \pm 0.7$ & $1.4 \pm 0.5$ & $1.9 \pm 0.6$ & $1.8 \pm 0.9$ \\
\hline $16: 4 n-3$ & $2.6 \pm 1.2$ & $0.8 \pm 0.3$ & $1.3 \pm 0.6$ & $1.2 \pm 0.4$ \\
\hline $16: 4 n-1$ & $1.6 \pm 0.7$ & $1.5 \pm 0.8$ & $0.9 \pm 0.6$ & $1.0 \pm 0.6$ \\
\hline 18:0 & $14.2 \pm 1.6$ & $13.1 \pm 0.8$ & $11.6 \pm 0.7$ & $11.7 \pm 0.5$ \\
\hline $18: 1 n-9$ & $20.6 \pm 4.1$ & $18.5 \pm 3.4$ & $32.3 \pm 3.9$ & $27.9 \pm 3.5$ \\
\hline $18: 1 n-7$ & $11.9 \pm 2.4$ & $9.5 \pm 1.0$ & $13.9 \pm 1.2$ & $12.5 \pm 0.8$ \\
\hline $18: 2 n-6$ & $8.6 \pm 1.5$ & $9.2 \pm 1.6$ & $12.4 \pm 1.2$ & $12.9 \pm 1.0$ \\
\hline $18: 2 n-4$ & $2.0 \pm 0.4$ & $1.5 \pm 0.2$ & $2.1 \pm 0.2$ & $2.1 \pm 0.2$ \\
\hline $18: 3 n-6$ & $2.2 \pm 0.8$ & $1.5 \pm 0.4$ & $2.5 \pm 0.4$ & $2.3 \pm 0.2$ \\
\hline $18: 3 n-4$ & $2.2 \pm 0.7$ & $1.5 \pm 0.3$ & $2.4 \pm 0.4$ & $2.0 \pm 0.3$ \\
\hline $18: 3 n-3$ & $6.6 \pm 1.4$ & $6.9 \pm 0.9$ & $7.9 \pm 0.6$ & $8.7 \pm 0.7$ \\
\hline $18: 3 n-1$ & $1.2 \pm 0.7$ & $1.2 \pm 0.3$ & $1.1 \pm 0.3$ & $1.5 \pm 0.3$ \\
\hline $18: 4 n-3$ & $3.5 \pm 0.7$ & $4.0 \pm 1.2$ & $4.9 \pm 0.7$ & $5.6 \pm 0.7$ \\
\hline $18: 4 n-1$ & $1.3 \pm 0.6$ & $0.4 \pm 0.5$ & $0.9 \pm 0.5$ & $1.2 \pm 0.6$ \\
\hline $20: 0$ & $2.1 \pm 0.7$ & $2.8 \pm 0.7$ & $3.1 \pm 0.6$ & $2.8 \pm 0.8$ \\
\hline $20: 1 n-11$ & $1.7 \pm 1.0$ & $0.8 \pm 0.5$ & $1.9 \pm 0.8$ & $1.4 \pm 0.4$ \\
\hline $20: 1 n-9$ & $6.0 \pm 1.4$ & $4.2 \pm 0.8$ & $7.9 \pm 0.9$ & $7.1 \pm 0.9$ \\
\hline $20: 1 n-7$ & $2.5 \pm 0.4$ & $2.5 \pm 0.3$ & $3.8 \pm 0.4$ & $4.1 \pm 0.6$ \\
\hline $20: 2 n-9$ & $0.8 \pm 0.6$ & $1.4 \pm 0.8$ & $1.3 \pm 0.4$ & $1.2 \pm 0.4$ \\
\hline $20: 2 n-6$ & $3.8 \pm 0.9$ & $4.7 \pm 0.9$ & $6.8 \pm 1.3$ & $7.5 \pm 1.0$ \\
\hline $20: 3 n-6$ & $3.4 \pm 0.5$ & $3.6 \pm 0.4$ & $4.4 \pm 0.5$ & $4.0 \pm 0.4$ \\
\hline $20: 4 n-6$ & $13.8 \pm 1.7$ & $14.2 \pm 1.3$ & $10.1 \pm 1.1$ & $10.0 \pm 1.2$ \\
\hline $20: 3 n-3$ & $3.5 \pm 0.7$ & $4.5 \pm 0.9$ & $5.1 \pm 0.6$ & $6.6 \pm 0.7$ \\
\hline $20: 4 n-3$ & $6.1 \pm 1.2$ & $8.2 \pm 1.3$ & $8.8 \pm 1.1$ & $10.8 \pm 0.9$ \\
\hline $20: 5 n-3$ & $18.0 \pm 2.9$ & $15.7 \pm 1.2$ & $11.8 \pm 2.1$ & $12.2 \pm 1.8$ \\
\hline $22: 1 n-11$ & $1.8 \pm 1.7$ & $0.9 \pm 0.5$ & $1.0 \pm 1.3$ & $0.9 \pm 0.4$ \\
\hline $22: 1 n-9$ & $2.2 \pm 0.5$ & $2.4 \pm 0.4$ & $3.3 \pm 0.4$ & $3.1 \pm 0.4$ \\
\hline $22: 1 n-7$ & $1.2 \pm 0.6$ & $1.0 \pm 0.5$ & $1.1 \pm 0.3$ & $1.6 \pm 0.4$ \\
\hline $22: 2 n-6$ & $1.4 \pm 0.5$ & $1.7 \pm 0.6$ & $3.0 \pm 0.5$ & $4.0 \pm 0.8$ \\
\hline $21: 5 n-3$ & $0.9 \pm 0.6$ & $1.8 \pm 0.6$ & $2.2 \pm 0.6$ & $1.6 \pm 0.9$ \\
\hline $22: 4 n-6$ & $0.2 \pm 0.5$ & $1.0 \pm 1.6$ & $0.3 \pm 0.6$ & $1.6 \pm 1.7$ \\
\hline $22: 5 n-6$ & $7.6 \pm 1.1$ & $10.7 \pm 1.4$ & $7.7 \pm 0.7$ & $9.6 \pm 1.4$ \\
\hline $22: 4 n-3$ & $2.3 \pm 0.9$ & $4.2 \pm 1.3$ & $5.1 \pm 0.9$ & $7.2 \pm 1.7$ \\
\hline $22: 5 n-3$ & $10.4 \pm 0.9$ & $10.8 \pm 0.6$ & $10.4 \pm 2.4$ & $11.1 \pm 0.7$ \\
\hline $22: 6 n-3$ & $33.9 \pm 5.6$ & $38.9 \pm 4.3$ & $23.1 \pm 3.7$ & $26.3 \pm 4.7$ \\
\hline
\end{tabular}

Note: Fatty acids are measured as percentage $(\% \pm S D)$.
FactoMineR and among arms of the lake. Pairwise post hoc comparison (Bonferroni corrected) also followed to test differences among arms of the lake (i.e., spatial variation). Finally, the fatty acid groups determined by FactoMineR were tested for differences in depth of capture using one-way analysis of similarities (ANOSIM) with 9,999 permutations using PAST 3. 


\section{3 | Life history}

To determine whether growth differed among groups of fish with different fatty acid profiles, length-age models were compared among groups using the Von Bertalanffy length-age model fit to length at age-of-capture of individual fish (Quinn \& Deriso, 1999):

$$
L_{t}=L_{\infty}\left(1-e^{-K\left(t-t_{0}\right)}\right)^{\varepsilon}
$$

The length-age model describes length $L_{t}$ at age-of-capture $t$ as a function of theoretical maximum length $\left(L_{\infty}=\mathrm{mm}\right)$, instantaneous rate at which $L_{t}$ approaches $L_{\infty}(K=1$ /year), theoretical age-at-zero length $\left(t_{0}=\right.$ years), and multiplicative error $(\varepsilon)$. Model parameters, $L_{\infty}, K$, and $t_{0}$, and associated standard errors were estimated using nonlinear regression. Residual sums-of-squares were compared between a full model (separate models for each group) to a reduced model (a single model for all groups) in a likelihood-ratio test (Hosmer et al., 2000). If the likelihood-ratio test was significant $(p \leq .05)$, we concluded that growth differed among groups identified by fatty acids. If the likelihood-ratio test was not significant $(p>.05)$, we concluded that growth did not differ among groups. The same test was repeated for each pair of groups, with and without giant individuals (fork length $\geq 900 \mathrm{~mm}$ ) included in each group, to isolate the influence of this subset in our size-at-age comparison due to the prevalence of giants in one of the groups (see Results). Finally, to determine whether fatty acid groups were an artifact of sex or maturity status, similarity of numbers of males versus females and resting versus nonresting individuals was tested using chi-square contingency table analysis (Zar, 2010).

\section{4 | Genetic analyses}

To determine whether genetic differences existed among individuals expressing different feeding strategies, the 79 lake trout classified by fatty acid composition into four groups were genotyped to determine genetic variation and structure within and among groups. To allow a sample size sufficient for making a genetic comparison of giants to the other dietary groups, 22 additional individuals determined nonrandomly by their size ( $\geq 900 \mathrm{~mm}$; giant subset) from the 2002-2015 collections were added to giants processed for fatty acids, for a total of 39 giants. Lake trout DNA was extracted from pectoral fin tissue preserved in ethanol using DNEasy extraction kits (Qiagen Inc., Valencia, CA) following manufacturer protocols. Piscivorous groups were assayed using a suite of 23 putatively neutral microsatellite markers amplified in four multiplexes previously described in Harris et al. (2015). Amplified microsatellite fragments were analyzed using an automated sequencer ( $\mathrm{ABI}$ 3130xl Genetic Analyzer; Applied Biosystems, Foster City, CA). The LIZ 600 size standard was incorporated for allele base-size determination. All genotypes were scored using GeneMapper software ver. 4.0 (Applied Biosystems) and then manually inspected to ensure accuracy.
The program MICROCHECKER ver. 2.2.0.3 (Van Oosterhout et al., 2004) was used to identify genotyping errors, specifically null alleles and large allele dropout. Observed and expected heterozygosity $\left(H_{E}\right.$ and $H_{\mathrm{O}}$ ) were calculated using GENEPOP ver. 4.2 (Rousset, 2008). The program HP-RARE ver. 1.1 (Kalinowski, 2005) was used to determine the number of alleles, allelic richness, and private allelic richness for each group, sampling 22 genes in each sample. Tests of departure from Hardy-Weinberg equilibrium and genotypic linkage disequilibrium within each sample (i.e., for each fatty acid grouping and the Giant subset) were conducted in GENEPOP using default values for both. Results from all tests were compared with an adjusted alpha $(\alpha=0.05)$ following the false discovery rate procedure (Narum, 2006).

We used the POWSIM V. 4.1 analysis to assess the statistical power of our microsatellite data set given the observed allelic frequencies within our samples in detecting significant genetic differentiation between sampling groups (Ryman \& Palm, 2006). For POWSIM analyses, we assumed that lake trout within our study diverged from a common baseline population with the same allelic frequencies as observed in our contemporary samples. Simulations were performed with an effective population size of 5,000 to yield values of $F_{\mathrm{ST}}$ of $0.01,0.005$, and 0.001 . The significance of tests in POWSIM was evaluated using Fisher's exact test and the chi-square test and the statistical power was determined as the proportion of simulations for which these tests showed a significant deviation from zero. All simulations were performed with 1,000 iterations.

Genetic structuring was tested among lake trout groups using several different methods. First, genotypic differentiation among lake trout groups was calculated using log-likelihood $(G)$ based exact tests (Goudet et al., 1996) implemented in GENEPOP. Global $F_{\mathrm{ST}}$ $(\theta)$ (Weir \& Cockerham, 1984) was calculated in FSTAT ver. 2.9.3 (Goudet, 1995), and pairwise comparisons of $F_{\mathrm{ST}}$ between groups were calculated in ARLEQUIN ver. 3.5 (Excoffier et al., 2005) using 10,000 permutations. We then employed the Bayesian clustering program STRUCTURE V. 2.3.2 (Pritchard et al., 2000) to resolve the putative number of populations (i.e., genetic clusters $(K))$ within our samples. Owing to the remarkably low levels of genetic differentiation among lake trout in the Great Bear Lake (Harris et al., 2013, 2015), we employed the LOCPRIOR algorithm (Hubisz et al., 2009). The LOCPRIOR algorithm considered the location/sampling information as a prior in the model, which may perform better than the traditional STRUCTURE model when the genetic structure is weak (Hubisz et al., 2009). We also incorporated an admixture model with correlated allelic frequencies and the model was run with a burn-in period of 500,000 iterations and 500,000 Markov chain Monte Carlo iterations. We varied the potential number of populations $(K)$ from 1 to 10 , and we ran 20 iterations for each value of $K$. The STRUCTURE output was first processed in the program STRUCTURE HARVESTER (Earl, 2012), followed by the combination of results of independent runs of the program and compilation of results based on $\ln P(D)$ and the post hoc $\Delta K$ statistic of Evanno et al. (2005), to infer the most likely number of clusters. The best alignment of replicate runs was assessed with CLUMPP V. 1.1 (Jakobsson \& Rosenberg, 2007) and 
DISTRUCT V. 1.1 (Rosenberg, 2004) was then used to visualize the results. For STRUCTURE analyses, we reported both $\ln P(D)$ and the post hoc $\Delta K$ statistic.

Finally, discriminant analysis of principal components (DAPC) (Jombart et al., 2010) was implemented in the Adegenet package (Jombart, 2008) in R (Team, 2015) to identify the number of clusters. The number of clusters was identified using the find.clusters function (a sequential K-means clustering algorithm) and subsequent Bayesian Information Criterion (BIC), as suggested by Jombart et al. (2010). Stratified cross-validation (carried out with the function xvalDapc) was used to determine the optimal number of principal components to retain in the analysis.

\section{5 | Morphology}

Morphological variation was quantified for the 79 lake trout and used to compare fatty acid groupings (different feeding strategies) identified within the piscivorous ecotype. Twenty-three landmarks and 20 semi-landmarks, based on Chavarie et al. (2015), and fourteen linear measurements based on Muir et al. (2014), were used to characterize body and head shape from digital images. The combination of traditional and geometric ecotype metrics was used because relationships of an individual's morphology related to foraging (e.g., jaw size) and swimming (e.g., fin lengths and caudal peduncle depth) (Kahilainen et al., 2004; Kristjánsson et al., 2002; Webb, 1984). Landmarks and semi-landmarks were digitized in $\mathrm{x}$ and $\mathrm{y}$ coordinates using TPSDig2 software (http://life.bio.sunysb.edu/ecotype). Subsequently, digitized landmarks and semi-landmarks were processed in a series of Integrated Morphometrics Programs (IMP) version 8 (http://www2. canisius.edu/;sheets/ecotypesoft), using partial warp scores, which are thin-plate spline coefficients. Morphological methods and programs are described in Zelditch et al. (2012), and specific procedures were described in further detail by Chavarie et al. (2013). All morphological measurements were size-free, using centroid sizes or residuals from regressions on standard length (Zelditch et al., 2012).

Canonical variate analyses (CVA) were conducted on all morphological data, including body shape, head shape, and linear measurements, to determine whether morphological differentiation occurred among fatty acid groups. Body and head shape were analyzed using CVAGen8 from the IMP software (Zelditch et al., 2012), and for linear measurements, CVA was analyzed with SYSTAT (Systat Software Inc., Chicago, IL, USA). Single Factor Permutation MANOVA with 10,000 permutations tested for differences among groups and determined the percentage of variation explained for a grouping if a CVA was significant. For linear measurements, a Bonferroni-corrected post hoc test followed MANOVA to identify measurements that differed among group. Principal component analyses (PCA) were performed on body- and head-shape data using PCAGen8 (IMP software) to determine morphological variation among individuals within the data set. PC-ORD version 6 software (McCune \& Mefford, 2011) was used to perform a PCA on the linear measurements.

\section{3 | RESULTS}

\section{1 | Fatty acids}

On the basis of fatty acid composition, piscivorous lake trout were divided along a resource-use axis into four groups (1-4; Figure S2), containing 14, 16, 21, and 28 individuals, respectively (Figure 3 and Figure S2; Table 1). Average dissimilarity was 14.61 (SIMPER analysis), whereas the most discriminating 26 fatty acids, explaining together $~ 89 \%$ of the separation among groups, were as follows: 22:6n-3 (12.5\%), 18:1n-9 (10.8\%), 16:1n-7 (6.8\%), 20:5n-3 (5.0\%), 20:4n-6 (3.9\%), 18:2n-6 (3.8\%), $22: 4 n-3$ (3.7\%), 16:0 (3.5\%), 20:4n-3 (3.3\%), 18:1n7 (3.3\%), 20:2n-6 (3.1\%), 14:0 (2.8\%), 20:1n-9 (2.7\%), 22:5n-6 (2.7\%), 20:3n-3 (2.3\%), $22: 2 n-6$ (2.1\%), 18:0 (2.0\%), 18:3n-3 (1.9\%), 18:4n-3 (1.8\%), 22:4n-6 (1.7\%), 20:1n-7 (1.5\%), 22:5n-3 (1.4\%), 21:5n-3 (1.3\%), 22:1n-11 (1.2\%), 20:0 (1.2\%), 16:4n-3 (1.2\%), and 16:2n-4 (1.1\%) (Table 1). The first two axes of the fatty acid PCA explained $65.2 \%$ of the variation, and the four groups were supported by PERMANOVA $\left(F_{3,76}=23.9, p<.01\right)$ and pairwise comparisons between all pairs (all $p<.01$; Bonferroni corrected). Spatial differences in fatty acid composition were found among lake arms $\left(F_{4,76}=3.2, p<.01\right)$. Pairwise comparisons identified differences between Smith and McVicar arms ( $p=.02$; Bonferroni corrected; Figure S3). Interaction between fatty acid groups and arms was not significant $(p>.05)$. Finally, depth of capture did not differ among fatty acid groups $(p>.05)$. For all groups, most lake trout were caught between 0 and $20 \mathrm{~m}$ (Figure S4).

\section{2 | Life history}

Overall, life-history parameters did not differ among lake trout grouped by fatty acid composition, including length-age models (Figure 4; $F_{9,63}=1.58 ; p=.141$ ). With the giant subset included, growth differed between only Group 3 and Group $4\left(F_{3,41}=3.958\right.$; $p=.014)$, but not between any other pairs $(p>.1)$. Without Giants included (prevalence of Giants was higher in Group 3 than Group 1, Group 2, and Group 4), none of the pairs differed in length at age $(p>1)$, which suggests growth was similar among groups. The sex ratio was equally distributed among fatty acid groups (chisquare $=0.59 ; d f=3 ; p=.90$ ), and the chi-square test indicated that fatty acid groups did not differ either in numbers of males versus females nor resting versus nonresting individuals (males and females combined; chi-square $=3.92 ; d f=3 ; p=.27$ ).

\section{3 | Genetic differentiation}

Piscivorous lake trout groups displayed little genetic differentiation, except for the Giant subset, which differed slightly from other groups that were defined by fatty acids. MICROCHECKER identified two loci (OtsG253b and Sco102) that contained null alleles. These loci, along with nonvariable loci Sco218 and SSOSL456, were removed, leaving 19 informative loci for subsequent analyses. Descriptive 


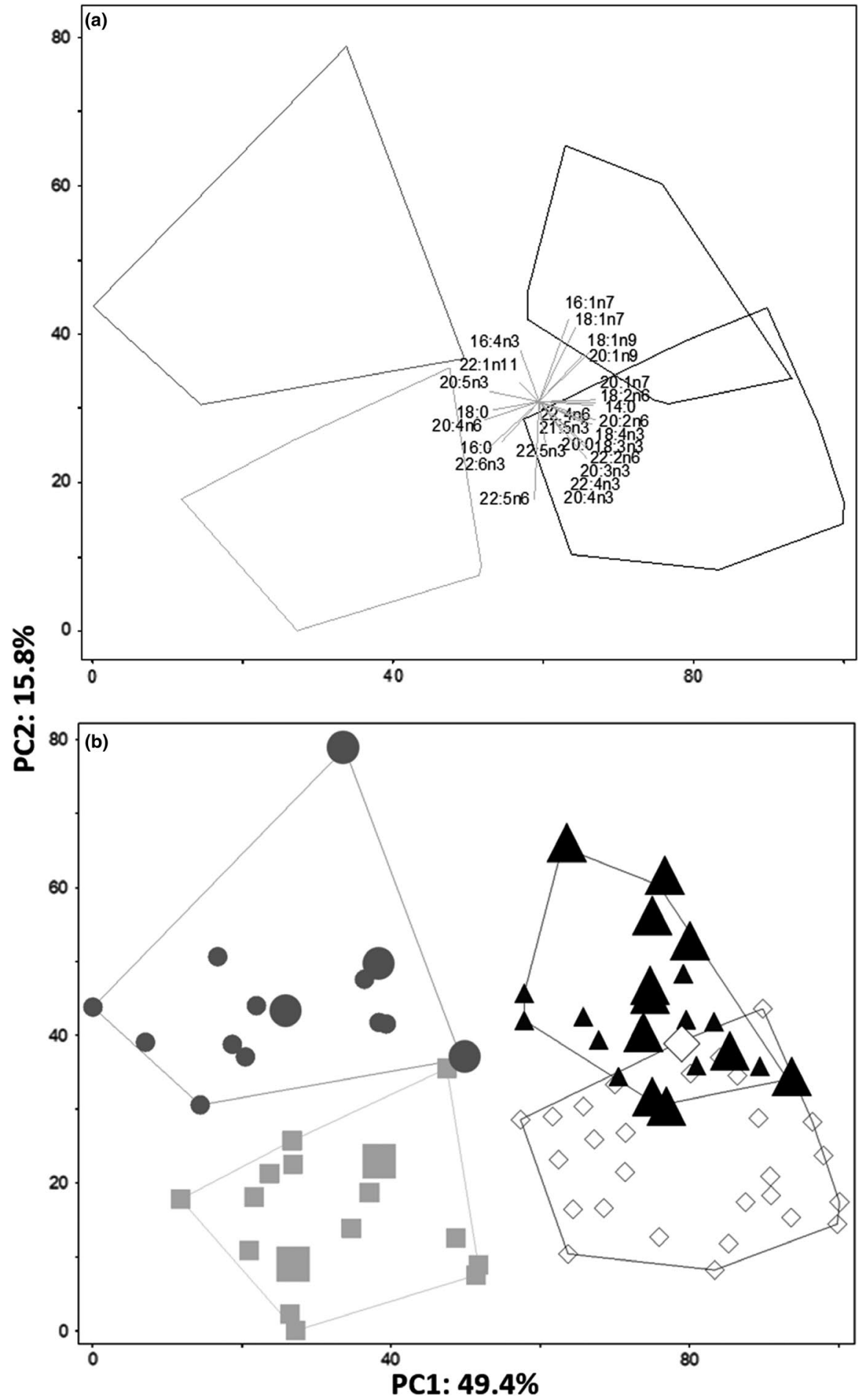

FIGURE 3 Principal component analysis of fatty acids of 79 Lake Trout classified as the piscivorous morph from Great Bear Lake, based on the most discriminating 26 fatty acids from SIMPER analysis, explaining together $\sim 89 \%$ of the separation among groups. (a) Vectors of individual fatty acids contributing to the positioning of piscivorous individuals and the convex hull delimitating group's position are shown. (b) Individual Lake Trout are represented as circle $=$ Group 1, square $=$ Group 2, triangle $=$ Group 3, and diamond = Group 4. To visualize their variation within and among groups, large symbols were used to depict individuals longer than $900 \mathrm{~mm}$ fork length, which were identified as the Giant subset in this study. Groups were defined by FactoMineR using fatty acids, and they are outlined by convex hulls

statistics of genetic variation were similar among groups. The number of alleles per locus ranged from four (Smm21) to 41 (SnaMSU10) and averaged 28.75 across all loci. Averaged observed heterozygosity ranged from 0.78 (Giant) to 0.83 (Group 1) while expected heterozygosity was 0.84 for all groups except Group 1 (0.85; Table 2). Allelic richness ranged from 9.57 (Group 2 and 4) to 9.87 (Group 1), while expected private allelic richness ranged from 0.87 (Group 3 ) to 1.08 (Group 2; Table 2). Only five of 95 tests (all of which involved different loci) showed significant departures from Hardy-Weinberg equilibrium after adjustment for false discovery rate (adjusted $\alpha=0.01)$. Of those five, all were heterozygote deficits and three involved the Giant subset. Only nine of 885 tests revealed significant linkage disequilibrium after adjusting for false discovery rate (adjusted $\alpha=0.0068$ ). No locus-pair linkage disequilibrium combinations were consistently significant, but seven of nine departures were in the Giant subset.

Using our microsatellite data set, the POWSIM analysis indicated a $100 \%$ power of detecting $F_{\mathrm{ST}}$ values as low of 0.01 and 
0.005. However, power was reduced to $77 \%$ when assessing genetic differentiation at a $F_{\mathrm{ST}}$ of 0.001 . Overall, our microsatellite data set (including the number of loci, alleles per locus, and sample sizes) had sufficient power to detect relatively low levels of genetic differentiation

Global genetic differentiation was extremely low $(\theta=0.001,95 \%$ c.i. $=-0.002-0.005)$ among the groups of piscivorous lake trout. Pairwise $F_{\mathrm{ST}}$ ranged from -0.004 to 0.016 (Table 3); comparisons that included Giants always differed the most from the other fatty acid groups, and they were involved in the only significant pairwise comparisons ( $p<.05$, Table 3). The $F_{\text {ST }}$ values for the Giant versus. Groups 1 and 4 were generally similar to genetic differentiation among the four original lake trout ecotypes in Great Bear Lake, except for Ecotype 1 versus Ecotype 2 (Table 3). Bayesian clustering implemented in STRUCTURE provided evidence for two genetic clusters when evaluating both In $\mathrm{P}(\mathrm{D})$ or $\Delta K$ (Table S2). The admixture plot based on $K=2$ showed no clear genetic structure between groups defined by fatty acid analysis; however, some differentiation of the Giant subset from the fatty acid groups was observed (Figure 5).

Finally, the Bayesian information criterion in the DAPC analysis (BIC $=185.42$, Table S3, Figure S5a) suggested that two clusters best explained genetic structure in our study (30 PCs retained as suggested by the cross-validation procedure; Figure S5b). A compoplot (barplot showing the probabilities of assignment of individuals to the different clusters) for $K=2$ revealed no clear genetic structure

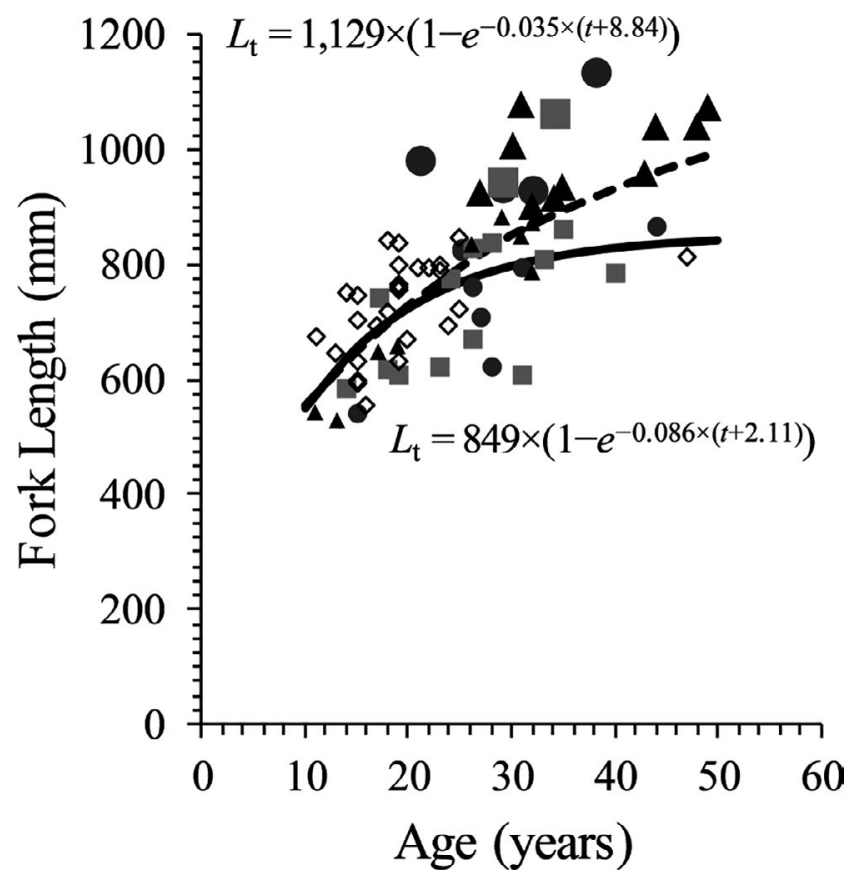

FIGURE 4 Fork length (mm) at age (years) for four groups of piscivorous Lake Trout sampled from Great Bear Lake in 20022015 (Group 1 = squares; Group 2 = circles; Group 3 = triangles; diamond = Group 4). Large symbols depict Giants (FL > $900 \mathrm{~mm}$ ) within each group. The von Bertalanffy length-age models are depicted as a solid line (without Giants) and a dashed line (with Giants) between two groups identified by the DAPC analysis except for the Giant group, which appeared to have more individuals assigned to cluster two (Figure 5). Density plots of the discriminant function, however, suggested that the two clusters identified through the DAPC analysis were mostly nonoverlapping (Figure S5c).

\section{4 | Morphology}

Morphological variation was low among the four dietary groups within the piscivorous ecotype. The first canonical axis for body shape CVA was significant ( $p \leq .05$ ), but head shape CVA revealed no significant canonical axes $(p>.05)$ in groupings (Figure 6a-c). MANOVAs for body and head shape were not significant $(p>.05)$. Linear measurements CVA revealed one significant canonical axis $(p \leq .05)$. MANOVA permutation tests confirmed differences in linear measurements among groups $(p=.047)$. Most distinctions were related to linear measurements of heads, with upper and lower jaws, head depth, and snout-eye lengths differing between Group 3 and Group 4 ( $p \leq .05$ ), and head length differing between Group 1 and 4 ( $p=.03$; Figure 7). Caudal peduncle length and anal fin length differed marginally between Groups 2 versus $3(p=.068)$ and Groups 1 versus 3 ( $p=.075$ ), respectively. The first two PCA axes explained $44.3 \%$ and $12.3 \%$ of variation for body shape, $35.1 \%$ and $30.7 \%$ of variation for head shape, and $39.6 \%$ and $20.9 \%$ for linear measurements (Figure 6d-f).

\section{4 | DISCUSSION}

A common assumption in polyphenism is that partitioning and variability of resource use will occur predominantly among ecotypes rather than within ecotypes. In contrast, homogeneity of resource use is anticipated to occur within ecotypes, be spatially and temporally stable, and provide the selection opportunity for specialization (Amundsen et al., 2008; Knudsen et al., 2010; Svanbäck \& Persson, 2004). However, this study provided evidence that variation occurred within an ecotype due to diet specialization among individuals, possibly a precursor to further population diversification via fine-scale ecological selection (Richardson et al., 2014; Vonlanthen et al., 2009).

Using fatty acids as dietary biomarkers, four distinct patterns of resource use were identified within the piscivorous lake trout of Great Bear Lake (Figure 2). Groups 3 and 4 had the most overlap, and these groups were characterized by $\mathrm{C} 20$ and $\mathrm{C} 22$ monounsaturates, biomarkers of a food web based on pelagic or deep-water copepods (Ahlgren et al., 2009; Happel et al., 2017; Hoffmann, 2017; Loseto et al., 2009; Stowasser et al., 2006). Specifically, 20:1n-9 is associated with calanoid copepods known to be particularly important in northern pelagic food webs (Ahlgren et al., 2009; Budge et al., 2006; Kattner et al., 1998; Loseto et al., 2009). High levels of 14:0, 18:3n-3 and 18:4n-3 fatty acids within groups 3 and 4 are also associated with pelagic environments (Scharnweber et al., 2016; Tucker 
TABLE 2 Number of individuals genotyped (N), number of alleles $\left(N_{A}\right)$, expected heterozygosity $\left(H_{E}\right)$, observed heterozygosity $\left(H_{O}\right)$, allelic richness $\left(A_{R}\right)$ and private allelic richness $\left(P A_{R}\right)$ within fatty acid groups identified within a piscivorous morphotype of Lake Trout from Canada's Great Bear Lake

\begin{tabular}{lllllll} 
& $N$ & $N_{A}$ & $H_{E}$ & $H_{\mathrm{O}}$ & $A_{R}$ & $P_{R}$ \\
\hline Group 1 & 12 & 10.16 & 0.85 & 0.83 & 9.87 & 1.08 \\
Group 2 & 16 & 11.26 & 0.84 & 0.82 & 9.57 & 0.99 \\
\hline Group 3 & 20 & 12.32 & 0.84 & 0.81 & 9.70 & 0.87 \\
Group 4 & 28 & 14.11 & 0.84 & 0.81 & 9.57 & 0.98 \\
\hline Giant & 39 & 15.95 & 0.84 & 0.78 & 9.69 & 1.05 \\
\hline
\end{tabular}

et al., 2008), although high levels of $18: 2 n-6$ and $18: 3 n-3$ have also been associated with terrestrial markers (Budge \& Parrish, 1998; Budge et al., 2001; Hoffmann, 2017).
Groups 1 and 2 were characterized by high concentrations of $16: 4 n-3,20: 4 n-6$, and 22:6n-3 found in diatom and dinoflagellate-based food webs, respectively. The fatty acid 20:4n-6 reflects a benthic feeding strategy (from benthic invertebrates to fish) (Stowasser et al., 2006; Tucker et al., 2008), whereas 22:6n-3 in pennate diatoms (Iverson, 2009) and filter feeders links planktonic dinoflagellates to benthic filter-feeding bivalves in a food web (Alfaro et al., 2006; Virtue et al., 2000). Relatively high concentrations of 16:0, 18:0, and 22:6n-3 and low concentrations of $16: 1 n-7$ supported the interpretation of carnivorous (or cannibalistic) dietary patterns or higher trophic position (Dalsgaard et al., 2003; Iverson, 2009; Iverson et al., 2004; Piché et al., 2010). Although the physiological state of individuals cannot be ruled out as internal drivers (Chavarie et al., 2020; Keva et al., 2019; Manor et al., 2014), individuals positioned between ends of principal components suggest a clinical pattern of resource use or habitat coupling (Vonlanthen et al., 2009),

TAB LE 3 Pairwise $F_{\mathrm{ST}}$ based on variation at microsatellite loci among Lake Trout morphs from Harris et al. (2015) and piscivorous fatty acid dietary groups from Great Bear Lake

\begin{tabular}{|c|c|c|c|c|c|c|c|c|}
\hline & Morph 1 & Morph 2 & Morph 3 & & Group 1 & Group 2 & Group 3 & $\begin{array}{l}\text { Group } \\
4\end{array}$ \\
\hline Morph 1 & & & & Group 1 & & & & \\
\hline Morph 3 & $0.004^{* *}$ & $0.007^{* *}$ & & Group 3 & 0.001 & -0.01 & & \\
\hline Morph 4 & $0.012^{* *}$ & $0.017^{* *}$ & $0.009^{* *}$ & Group 4 & 0.005 & -0.004 & -0.002 & \\
\hline
\end{tabular}

Note: Significant results are represented as follow: ${ }^{*}$ values are significant at an initial $\alpha$ of 0.05 , and ${ }^{* *}$ values are significant at an $\alpha$ of 0.02 subsequent false discovery rate adjustments for multiple comparisons.

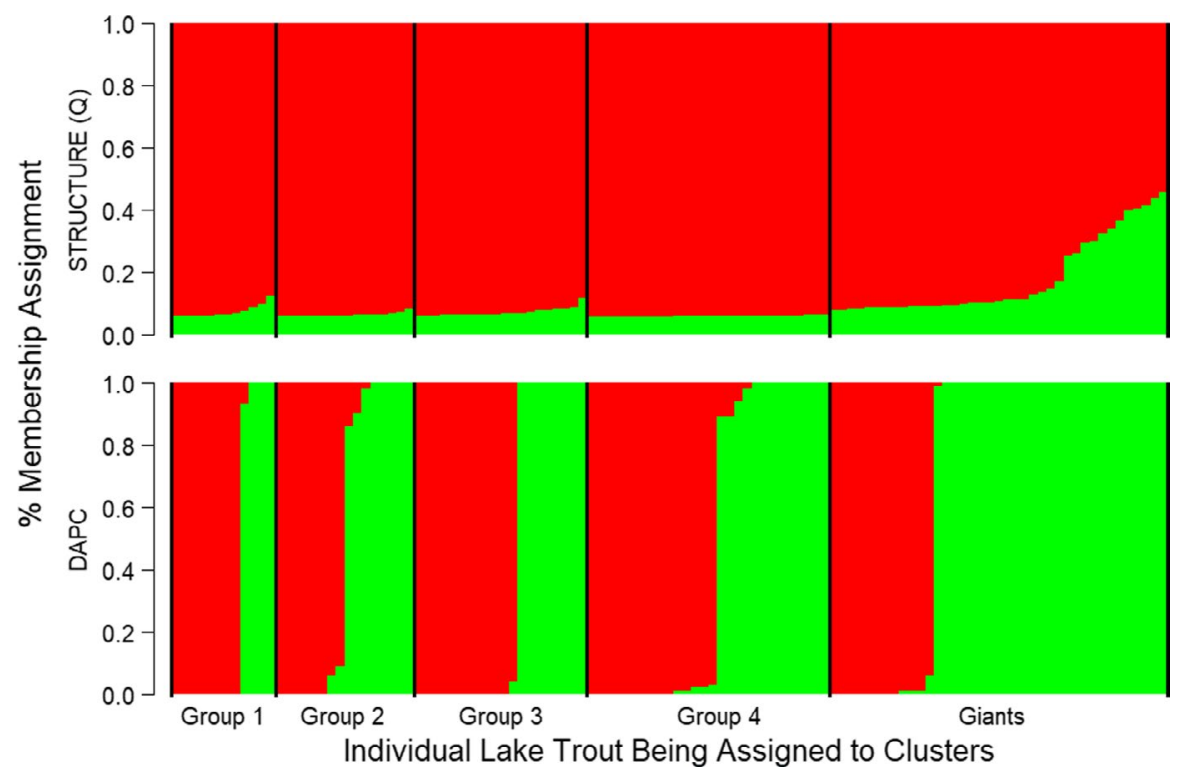

FIGURE 5 Results of the Bayesian clustering analysis implemented in the program STRUCTURE (B) and the compoplot of percent membership assignment revealed from the discriminant analysis of principal component (DAPC) analysis (B) for piscivorous Lake Trout from Great Bear Lake. The graph shows the admixture coefficient/percent membership assignment plot where each individual is represented as a vertical line partitioned into colored segments representative of an individual's fractional membership in any given cluster (K). The most likely number of genetic clusters was two in both the STRUCTURE analysis (based on In P[D] and the $\Delta K$ statistic of Evanno et al. (2005)) and DAPC analysis (based on the lowest BIC score and with 30 PCs retained) 
where borders among groups are neither abrupt nor obvious as they are part of a continuum (Hendry et al., 2009).

Sympatric divergence, in which barriers to gene flow are driven by selection between ecological niches, has been implicated in the evolution of ecological and morphological variation in fishes (Chavarie, Muir, et al., 2016; Hendry et al., 2007; Præbel et al., 2013). Size has a predominant influence on animal ecological and evolutionary aspects, from the potential of resource exploitation and niche differentiation, to spawning strategies (Kohda et al., 2008; Nagel \& Schluter, 1998; Werner \& Gilliam, 1984). In a fish population, associations between growth, body size, and niche use are frequently observed, but in this study, differences in growth models were not detected to influence the niche use and the individual specialization observed within the piscivorous ecotype. However, despite the limited ability of neutral microsatellite markers to detect patterns of functional divergence (Berg et al., 2016; Lamichhaney et al., 2016; Roesti et al., 2015), the significant genetic differentiation based on comparisons with Giant subset suggests some deviation from panmixis within the piscivorous ecotype. Such a genetic pattern displayed by the Giant subset, despite a lack of ecological discreteness, perhaps resulted from size-assortative mating and/or differences in timing and location of spawning (Nagel \& Schluter, 1998; Rueger et al., 2016; Servedio et al., 2011). Great Bear Lake is not the only lake in North America with an apparent divergence in lake trout body size; in Lake Mistassini, "Giant" individuals also differed genetically from other lake trout groups (Marin et al., 2016). The similarity based on lake trout body size between both lakes suggests analogous variables favoring partial reproductive isolation. Although alternative causes of genetic differentiation may be possible, due to the short time since the onset of divergence, postzygotic isolation seems unlikely in this system (e.g., prezygotic isolation generally evolves more rapidly Coyne \& Orr, 2004) and we therefore favor assortative mating based on size and location as an explanation for the low-level genetic divergence observed. Nonetheless, putative partial reproductive isolation within an ecotype adds to the complexity of diversification and speciation processes potentially occurring within lake trout in Great Bear Lake (Hendry, 2009; Nosil et al., 2009).

A central question arising from our analysis is what are the mechanisms behind these patterns of variation? As individual specialization can result in dietary subgroups and perhaps differences in habitat use among sections of a population, such interindividual variation within ecological subgroups could substantially
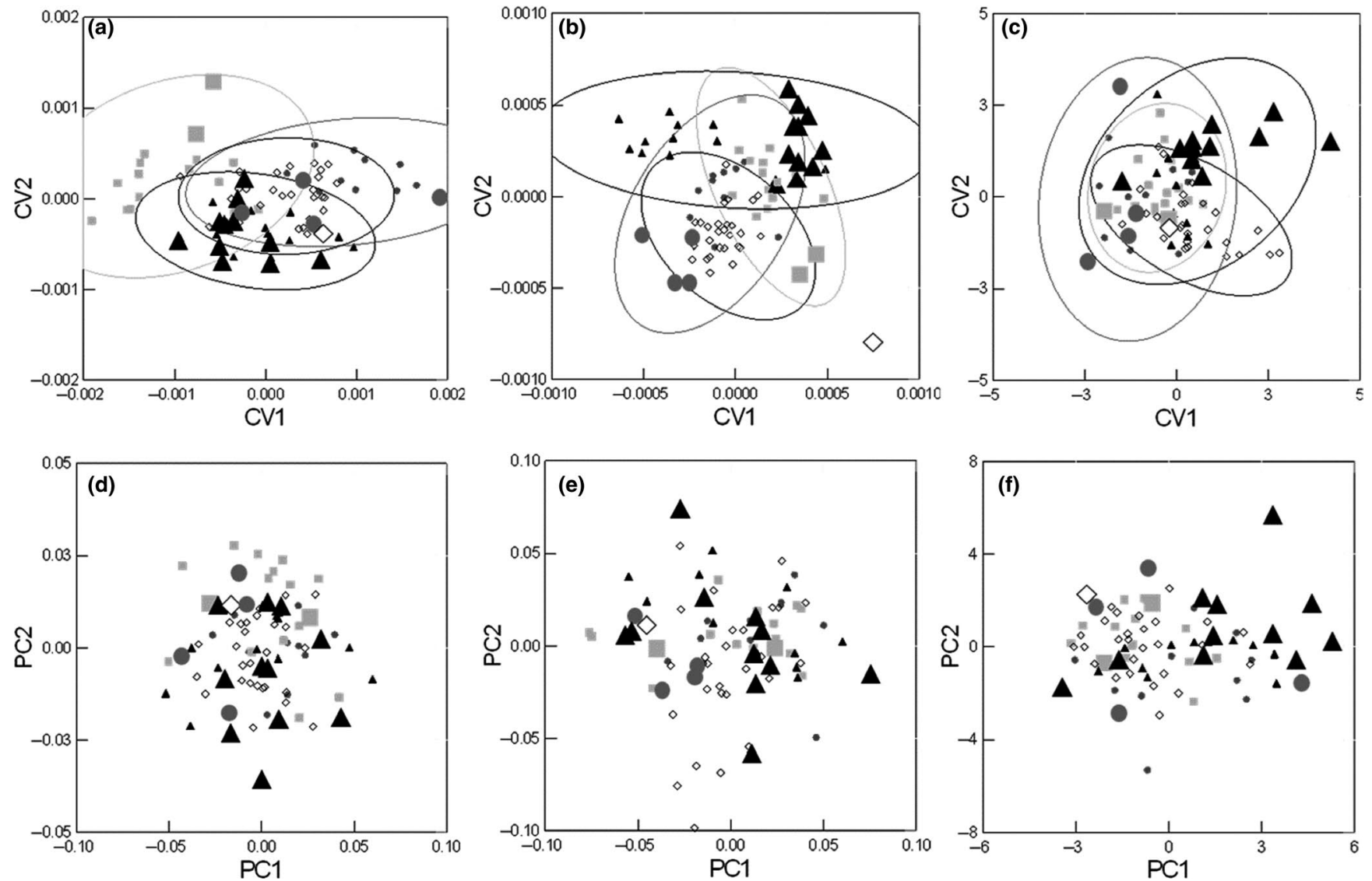

FIGURE 6 Canonical variate analyses (95\% ellipses) and principal component analysis of body shape (a, d), head shape (b, e), and linear measurements (c, f), respectively, of piscivorous Lake Trout represented as: square = Group 1, circle = Group 2, triangle = Group 3, and diamond $=$ Group 4 . The first two PCA axes explained $44.3 \%$ and $12.3 \%$ of variation for body shape, $35.1 \%$ and $30.7 \%$ of variation for head shape, and $39.6 \%$ and $20.9 \%$ for linear measurements (d, e, f). To visualize their variation within and among groups, individuals longer than $900 \mathrm{~mm}$ FL, which considered the Giant subset in this study, are depicted by larger symbols 

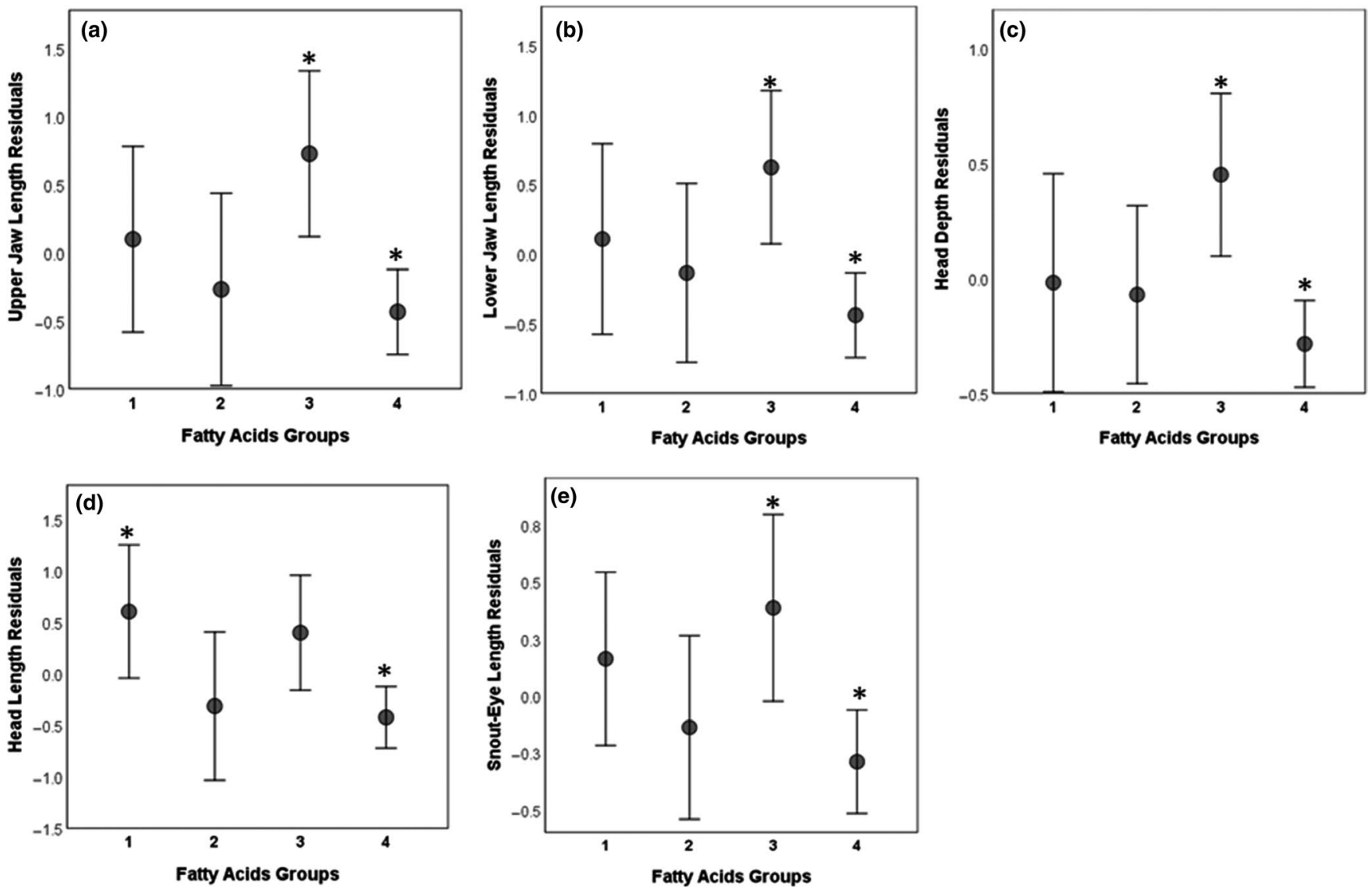

FIG URE 7 Residuals of mean $( \pm 95 \% \mathrm{Cl}$ ) size-standardized upper and lower jaw lengths, head depth and length, and snout-eye length among piscivorous Lake Trout groups. Grouping symbols are as follows: square = Group 1, circle = Group 2, triangle = Group 3, and diamond = Group 4, and significant differences are highlighted with *

influence processes of diversification (Araújo et al., 2008; Cloyed \& Eason, 2016). Among-individual resource specialization within an ecotype in a species-poor ecosystem like Great Bear Lake could reflect the diversifying force of intraspecific competition, lack of constraining effects of interspecific competition, the abundance and distribution of resources (e.g., temporal and spatial variation of resources), or some combination of these variables (Bolnick et al., 2007; Cloyed \& Eason, 2016). Multiple patterns of resource specialization within a single ecotype, as we see for lake trout in Great Bear Lake, contrasts with the expected pattern of trophic divergence among ecotypes and homogenization in habitat use or diet within an ecotype, a key assumption guiding the development of functional ecological theory (Svanbäck \& Persson, 2004; Violle et al., 2012). Expression of intraspecific divergence through habitat and foraging specialization is thought to drive selection on traits that enable more efficient use of resources (Schluter, 2000; Skulason \& Smith, 1995; Snorrason \& Skúlason, 2004).

In Great Bear Lake, multiple trophic generalists (which include the piscivores studied herein) coexist with one specialist lake trout ecotype (Chavarie, Harford, et al., 2016; Chavarie et al., 2018; Chavarie, Howland, Venturelli, et al., 2016). This contrasts with the more commonly reported observation of multiple specialist ecotypes (Elmer, 2016; Kassen, 2002). A generalist population, however, can be composed of several subsets of specialized individuals (Bolnick \& Paull, 2009; Bolnick et al., 2002, 2007). This broad distribution of trophic variation within a population appears to be the case within Great Bear Lake piscivores. The among-individual specialization may result, to some degree, from variable use of spatially separated resources and possibly temporally variable resources, both of which could be expected in a large northern lake (Figure S3; Costa et al., 2008; Cusa et al., 2019; Quevedo et al., 2009). Lake Trout has the reputation of being a mobile predator that displays flexible foraging behavior by moving across spatially disparate habitats, both within and among populations and seasons (Guzzo et al., 2017; Vander Zanden et al., 2000). Ecologically, among-individual resource specialization within an ecotype is another form of diversity (Araújo et al., 2008; Bolnick et al., 2003; Pires et al., 2011). Such diversity may increase stability and persistence of an ecotype within a system where energy resources are scarce and ephemeral (Cloyed \& Eason, 2016; Pfennig \& Pfennig, 2012; Smith et al., 2011). Whether the level of among-individual specialization within this ecotype is stable or not is a question that cannot be answered with our data.

Realized niche expansions are often linked to individuals of different morphologies and body sizes, with evidence of efficiency trade-offs among different resources (Cloyed \& Eason, 2016; 
Parent et al., 2014; Roughgarden, 1972; Svanbäck \& Persson, 2004). When a resource gradient exists, niche expansion can be achieved via genetic differentiation, phenotypic plasticity, or a combination of these processes (Bolnick \& Ballare, 2020; Parent et al., 2014). The apparent segregation of resource use, based on our fatty acid analyses, despite a lack of major morphological, growth, and genetic differentiation among the four dietary groups within the piscivorous ecotype, suggests that behavioral plasticity is causing the observed patterns of dietary differentiation. Plasticity may promote diversification by expanding the range of phenotypes on which selection can act (Nonaka et al., 2015; Pfennig et al., 2010; West-Eberhard, 2003). Theoretical models suggest that exploiting a wide range of resources is either costly or limited by constraints, but plasticity is favored when (a) spatial and temporal variation of resources are important, (b) dispersal is high, (c) environmental cues are reliable, (d) genetic variation for plasticity is high, and (e) cost/limits of plasticity are low (Ackermann et al., 2004; Hendry, 2016).

The expression of plasticity in response to ecological conditions (e.g., habitat structure, prey diversity) can increase fitness. While most studies of diet variation focus on morphological differences among ecotypes in a population, diet variation can also arise from behavioral, biochemical, cognitive, and social-rank differences that cause functional ecology to be expressed at a finer scale than at the ecotype level (McGill et al., 2006; Svanbäck \& Bolnick, 2005; Violle et al., 2012; Zhao et al., 2014). Indeed, behavioral plasticity likely has a temporal evolutionary advantage due to relatively reduced reliance on ecologically beneficial morphological adaptation (Smith et al., 2011; Svanbäck et al., 2009). The only detectable morphological differences among piscivorous groups we identified in Great Bear Lake were associated with jaw lengths, snout-eye distance, and head length and depth, which are strongly related to foraging opportunities (Adams \& Huntingford, 2002; Sušnik et al., 2006; Wainwright \& Price, 2016). In general, head characteristics (i.e., shape and dimension) have been linked to foraging efficiency associated with particular prey, environment, or both (Adams \& Huntingford, 2004; Bernatchez et al., 2016; Jonsson \& Jonsson, 2001). Some morphological characters likely express different degrees of plastic responses (adaptive or not), and thus may be expressed differently depending on the magnitude and time of exposure to heterogeneous environments (Hendry, 2016; Sharpe et al., 2008). For example, environmental components (e.g., habitat structure) appear to have stronger and faster effects on linear characters (e.g., jaw length) than on body shape (Chavarie et al., 2013, 2015; Sharpe et al., 2008). More specifically, diversification of fish via trophic specialization tends to reveal itself through differences in the trophic apparatus, particularly the mouth, which has direct contact with prey and substrate (Barlow and Munsey 1976; Maderbacher et al. 2008). Yet, the high trophic level of lake trout in Great Bear Lake, as top predators, could explain the small morphological differences detected herein because piscivory can limit diversification of feeding morphology in fishes (Collar et al., 2009; Svanbäck et al., 2015).

\section{5 | CONCLUSION}

Understanding ecological mechanisms of diversification is challenging (Ackermann et al., 2004). Divergence occurs along a continuum and in early stages, such as in postglacial lakes, morphological and dietary variation may not always be features that are related (Bolnick \& Ballare, 2020; Bolnick et al., 2007). The debate around diversification sequence (which diverges first, behavior, morphology, or ecology?) highlights the mosaic nature of intraspecific variation (Hendry et al., 2009a). In this study, we asked whether among-individual diet variation could be occurring within an ecotype by examining the fine-scale trophic variation of an early stage of sympatric divergence of lake trout in Great Bear Lake (i.e., postglacial, representing 567 generations; Harris et al., 2015). Due to presumed homogeneity, few studies have investigated dietary patterns and groupings within an ecotype. Thus, this study provides evidence that among-individual resource specialization can occur within an ecotype. The co-existence of multiple generalist ecotypes in Great Bear Lake (Chavarie, Harford, et al., 2016), combined with the individual specialization shown here in the piscivorous generalist ecotype, expands our understanding of niche use and expansion, plasticity, individual specialization, and intraspecific diversity in evolutionarily young populations.

Rapid divergence within relatively few generations and among-individual diet variation have both been demonstrated to be strong drivers of population dynamics (Ashley et al., 2003; Bolnick \& Ballare, 2020; Fussmann et al., 2007; Turcotte et al., 2011). In this study, the fine-grained trophic patterns shown within this ecotype suggested that ecological drivers (i.e., spatial variation, habitat use, prey diversity, and abundance) could have important effects on plasticity expression in early stages of divergence. Theory and experiments have demonstrated that among-individual diet variation can increase stability within a system (Agashe, 2009). Using a broad resource spectrum has been identified as an adaptive strategy for fishes living in Arctic environments, where food availability is patchily distributed and ephemeral (Dill, 1983; Kassen, 2002; Smith et al., 2011). Thus, it is no surprise that the trophic individual specialization within an ecotype was discovered within a northern lake.

\section{ACKNOWLEDGMENTS}

We thank one anonymous reviewer and Alexandra Tyers for their insightful readings and constructive suggestions. Déline Renewable Resources Council, Déline Lands and Finance Corporation, the community of Déline, Department of Fisheries and Oceans Canada in Hay River, and the Department of Environment and Natural Resources in Déline provided valuable help with field planning and logistics. We especially thank S. Buckley, J. Chavarie, G. Lafferty, M. Lindsey, M. Low, Z. Martin, S. Wiley, and C. Yukon, who helped lead sampling teams and coordinate logistics. The following individuals who helped conduct field sampling in various years are gratefully acknowledged: J. Baptiste, D. Baton, D. Betsidea, , L. Dueck, R. Eshenroder, G. Menacho, N. Modeste, I. 
Neyelle, L. Neyelle, M. Smirle, A. Swietzer, C. Takazo, A. Vital, F. Vital, B. Yukon, M. Yukon, T. Yukon and Charity, Cameron, and Cyre Yukon. .

\section{CONFLICT OF INTEREST}

The authors declare that they have no competing interests.

\section{AUTHOR CONTRIBUTIONS}

Louise Chavarie: Conceptualization (lead); datacuration (lead); formal analysis (lead); funding acquisition (supporting); investigation (equal); methodology (equal); resources (equal); validation (equal); visualization (equal); writing-original draft (lead); writing-review \& editing (equal). Kimberly L. Howland: Conceptualization (supporting); funding acquisition (lead); investigation (supporting); project administration (lead); resources (equal); supervision (supporting); writing-review \& editing (supporting). Les N. Harris: Formal analysis (supporting); visualization (supporting); writing-original draft (supporting); writing-review \& editing (supporting). Colin P. Gallagher: Datacuration (supporting); formal analysis (supporting); writing-review \& editing (supporting). Michael J. Hansen: Formal analysis (supporting); visualization (supporting); writing-original draft (supporting); writing-review \& editing (supporting). William M. Tonn: Project administration (supporting); writing-review \& editing (supporting). Andrew M. Muir: Funding acquisition (supporting); writing-review \& editing (supporting). Charles C. Krueger: Conceptualization (supporting); funding acquisition (supporting); investigation (supporting); project administration (supporting); supervision (lead); writing-review \& editing (equal).

\section{ETHICAL APPROVAL}

We declare that our experiments were performed in the respect of ethical rules. This protocol was approved by Department of Fisheries and Ocean Canada, Freshwater Institute Animal Care Committee Science Laboratories.

\section{DATA AVAILABILITY STATEMENT}

The data sets supporting the conclusions of this article are included within the article. Raw data will be available on Dryad (https://doi. org/10.5061/dryad.8w9ghx3ks).

\section{ORCID}

Louise Chavarie (iD https://orcid.org/0000-0002-1327-7872

\section{REFERENCES}

Ackermann, M., Doebeli, M., \& Gomulkiewicz, R. (2004). Evolution of niche width and adaptive diversification. Evolution, 58(12), 25992612. https://doi.org/10.1111/j.0014-3820.2004.tb01614.x

Adams, C. E., \& Huntingford, F. A. (2002). The functional significance of inherited differences in feeding morphology in a sympatric polymorphic population of Arctic charr. Evolutionary Ecology, 16(1), 15-25. https://doi.org/10.1023/A:1016014124038

Adams, C. E., \& Huntingford, F. A. (2004). Incipient speciation driven by phenotypic plasticity? Evidence from sympatric populations of Arctic charr. Biological Journal of the Linnean Society, 81(4), 611-618. https:// doi.org/10.1111/j.1095-8312.2004.00314.x
Agashe, D. A. (2009). Consequences of intraspecific genetic variation for population dynamics and niche expansion.

Ahlgren, G., Vrede, T., \& Goedkoop, W. (2009). Fatty acid ratios in freshwater fish, zooplankton and zoobenthos-are there specific optima? In M. Kainz, M. Brett, M. Arts (Eds.), Lipids in aquatic ecosystems (pp. 147-178). New York, NY: Springer. https://doi.org/10.1007/978-0387-89366-2_7

Alfaro, A. C., Thomas, F., Sergent, L., \& Duxbury, M. (2006). Identification of trophic interactions within an estuarine food web (northern New Zealand) using fatty acid biomarkers and stable isotopes. Estuarine, Coastal and Shelf Science, 70(1), 271-286. https://doi.org/10.1016/j. ecss.2006.06.017

Alfonso, N. R. (2004). Evidence for two morphotypes of lake charr Salvelinus namaycush, from Great Bear Lake, Northwest Territories, Canada. Environmental Biology of Fishes, 71, 21-32. https://doi. org/10.1023/B:EBFI.0000043176.61258.3d

Amundsen, P.-A., Knudsen, R., \& Klemetsen, A. (2008). Seasonal and ontogenetic variations in resource use by two sympatric Arctic charr morphs. Environmental Biology of Fishes, 83(1), 45-55. https://doi. org/10.1007/s10641-007-9262-1

Araújo, M. S., Bolnick, D. I., \& Layman, C. A. (2011). The ecological causes of individual specialisation. Ecology Letters, 14(9), 948-958. https:// doi.org/10.1111/j.1461-0248.2011.01662.x

Araújo, M. S., Guimarães, P. R., Svanbäck, R., Pinheiro, A., Guimarães, P., Reis, S. F. D., Bolnick, D. I. (2008). Network analysis reveals contrasting effects of intraspecific competition on individual vs. population diets. Ecology, 89(7), 1981-1993. https://doi.org/10.1890/07-0630.1

Ashley, M. V., Willson, M. F., Pergams, O. R., O'Dowd, D. J., Gende, S. M., \& Brown, J. S. (2003). Evolutionarily enlightened management. Biological Conservation, 111(2), 115-123. https://doi.org/10.1016/ S0006-3207(02)00279-3

Barlow, G. W., \& Munsey, J. W. (1976). The red devil-Midas-arrow cichlid species complex in Nicaragua. In T. B. Thorson (Ed.), Investigations of the ichthyofauna of Nicaraguan lakes (pp. 359-369). Lincoln: University of Nebraska Press.

Berg, P. R., Star, B., Pampoulie, C., Sodeland, M., Barth, J. M. I., Knutsen, H., Jakobsen, K. S., \& Jentoft, S. (2016). Three chromosomal rearrangements promote genomic divergence between migratory and stationary ecotypes of Atlantic cod. Scientific Reports, 6, 23246. https://doi.org/10.1038/srep23246

Bernatchez, S., Laporte, M., Perrier, C., Sirois, P., \& Bernatchez, L. (2016). Investigating genomic and phenotypic parallelism between piscivorous and planktivorous lake trout (Salvelinus namaycush) ecotypes by means of RADseq and morphometrics analyses. Molecular Ecology, 25(19), 4773-4792.

Bolnick, D. I., \& Ballare, K. M. (2020). Resource diversity promotes among-individual diet variation, but not genomic diversity, in lake stickleback. Ecology Letters, 23(3), 495-505. https://doi.org/10.1111/ ele.13448

Bolnick, D. I., Ingram, T., Stutz, W. E., Snowberg, L. K., Lau, O. L., \& Paull, J. S. (2010). Ecological release from interspecific competition leads to decoupled changes in population and individual niche width. Proceedings of the Royal Society B: Biological Sciences, 277(1689), 1789-1797. https://doi.org/10.1098/rspb.2010.0018

Bolnick, D. I., \& Paull, J. S. (2009). Morphological and dietary differences between individuals are weakly but positively correlated within a population of threespine stickleback. Evolutionary Ecology Research, 11(8), 1217-1233.

Bolnick, D. I., Svanbäck, R., Araújo, M. S., \& Persson, L. (2007). Comparative support for the niche variation hypothesis that more generalized populations also are more heterogeneous. Proceedings of the National Academy of Sciences, 104(24), 10075-10079. https://doi. org/10.1073/pnas.0703743104

Bolnick, D. I., Svanbäck, R., Fordyce, J. A., Yang, L. H., Davis, J. M., Hulsey, C. D., \& Forister, M. L. (2003). The ecology of individuals: Incidence 
and implications of individual specialization. American Naturalist, 161(1), 1-28. https://doi.org/10.1086/343878

Bolnick, D. I., Yang, L. H., Fordyce, J. A., Davis, J. M., \& Svanbäck, R. (2002). Measuring individual-level resource specialization. Ecology, 83(10), 2936-2941.10.1890/0012-9658(2002)083[2936:MILRS]2.0 . $\mathrm{CO} ; 2$

Budge, S. M., Iverson, S. J., \& Koopman, H. N. (2006). Studying trophic ecology in marine ecosystems using fatty acids: A primer on analysis and interpretation. Marine Mammal Science, 22(4), 759-801. https:// doi.org/10.1111/j.1748-7692.2006.00079.x

Budge, S. M., \& Parrish, C. C. (1998). Lipid biogeochemistry of plankton, settling matter and sediments in Trinity Bay, Newfoundland. II. Fatty acids. Organic Geochemistry, 29(5), 1547-1559.

Budge, S., Parrish, C., \& Mckenzie, C. (2001). Fatty acid composition of phytoplankton, settling particulate matter and sediments at a sheltered bivalve aquaculture site. Marine Chemistry, 76(4), 285-303. https://doi.org/10.1016/S0304-4203(01)00068-8

Chaguaceda, F., Eklöv, P., \& Scharnweber, K. (2020). Regulation of fatty acid composition related to ontogenetic changes and niche differentiation of a common aquatic consumer. Oecologia, 193(2), 325-336. https://doi.org/10.1007/s00442-020-04668-y

Chavarie, L., Harford, W. J., Howland, K. L., Fitzsimons, J., Muir, A. M., Krueger, C. C., \& Tonn, W. M. (2016). Multiple generalist morphs of Lake Trout: Avoiding constraints on the evolution of intraspecific divergence? Ecology and Evolution, 6, 7727-7741. https://doi. org/10.1002/ece3.2506

Chavarie, L., Hoffmann, J., Muir, A. M., Krueger, C. C., Bronte, C. R., Howland, K. L., Gallagher, C. P., Sitar, S. P., Hansen, M. J., Vinson, M. R., Baker, L. F., Loseto, L. L., Tonn, W. M., \& Swanson, H. K. (2020). Dietary versus nondietary fatty acid profiles of lake trout ecotypes from Lake Superior and Great Bear Lake: Are fish really what they eat? Canadian Journal of Fisheries and Aquatic Sciences, 77(7), 12091220. https://doi.org/10.1139/cjfas-2019-0343

Chavarie, L., Howland, K., Gallagher, C., \& Tonn, W. (2016). Fatty acid signatures and stomach contents of four sympatric Lake Trout: Assessment of trophic patterns among morphotypes in Great Bear Lake. Ecology of Freshwater Fish, 25, 109-124. https://doi. org/10.1111/eff.12195

Chavarie, L., Howland, K. L., Harris, L. N., Hansen, M. J., Harford, W. J., Gallagher, C. P., Baillie, S. M., Malley, B., Tonn, W. M., Muir, A. M., \& Krueger, C. C. (2018). From top to bottom: Do Lake Trout diversify along a depth gradient in Great Bear Lake, NT, Canada? PLoS One, 13(3), e0193925. https://doi.org/10.1371/journal.pone.0193925

Chavarie, L., Howland, K., Harris, L., \& Tonn, W. (2015). Polymorphism in lake trout in Great Bear Lake: Intra-lake morphological diversification at two spatial scales. Biological Journal of the Linnean Society, 114(1), 109-125. https://doi.org/10.1111/bij.12398

Chavarie, L., Howland, K. L., \& Tonn, W. M. (2013). Sympatric polymorphism in lake trout: The coexistence of multiple shallow-water morphotypes in Great Bear Lake. Transactions of the American Fisheries Society, 142(3), 814-823. https://doi.org/10.1080/00028 487.2013.763855

Chavarie, L., Howland, K., Venturelli, P., Kissinger, B. C., Tallman, R., \& Tonn, W. (2016). Life-history variation among four shallow-water morphotypes of lake trout from Great Bear Lake, Canada. Journal of Great Lakes Research, 42(2), 193-203. https://doi.org/10.1016/j. jglr.2015.07.006

Chavarie, L., Muir, A. M., Zimmerman, M. S., Baillie, S. M., Hansen, M. J., Nate, N. A., Yule, D. L., Middel, T., Bentzen, P., \& Krueger, C. C. (2016). Challenge to the model of lake charr evolution: Shallowand deep-water morphs exist within a small postglacial lake. Biological Journal of the Linnean Society, 120(3), 578-603. https://doi. org/10.1111/bij.12913

Cloyed, C. S., \& Eason, P. K. (2016). Different ecological conditions support individual specialization in closely related, ecologically similar species. Evolutionary Ecology, 30(3), 379-400. https://doi. org/10.1007/s10682-016-9825-8

Collar, D. C., O'Meara, B. C., Wainwright, P. C., \& Near, T. J. (2009). Piscivory limits diversification of feeding morphology in centrarchid fishes. Evolution, 63(6), 1557-1573. https://doi. org/10.1111/j.1558-5646.2009.00626.x

Costa, G. C., Mesquita, D. O., Colli, G. R., \& Vitt, L. J. (2008). Niche expansion and the niche variation hypothesis: Does the degree of individual variation increase in depauperate assemblages? The American Naturalist, 172(6), 868-877. https://doi. org/10.1086/592998

Coyne, J. A., \& Orr, H. A. (2004). Speciation (Vol. 37). Sinauer Associates.

Cusa, M., Berge, J., \& Varpe, Ø. (2019). Seasonal shifts in feeding patterns: Individual and population realized specialization in a high Arctic fish. Ecology and Evolution, 9(19), 11112-11121. https://doi. org/10.1002/ece3.5615

Dalsgaard, J., St. John, M., Kattner, G., Müller-Navarra, D., \& Hagen, W. (2003). Fatty acid trophic markers in the pelagic marine environment. Advances in Marine Biology, 46, 225-340.

De Jong, G. (2005). Evolution of phenotypic plasticity: Patterns of plasticity and the emergence of ecotypes. New Phytologist, 166(1), 101118. https://doi.org/10.1111/j.1469-8137.2005.01322.x

De León, L. F., Rolshausen, G., Bermingham, E., Podos, J., \& Hendry, A. P. (2012). Individual specialization and the seeds of adaptive radiation in Darwin's finches. Evolutionary Ecology Research, 14(4), 365-380.

Dill, L. M. (1983). Adaptive flexibility in the foraging behavior of fishes. Canadian Journal of Fisheries and Aquatic Sciences, 40(4), 398-408. https://doi.org/10.1139/f83-058

Duerksen, S. W., Thiemann, G. W., Budge, S. M., Poulin, M., Niemi, A., \& Michel, C. (2014). Large, omega-3 rich, pelagic diatoms under Arctic sea ice: Sources and implications for food webs. PLoS One, 9(12), e114070. https://doi.org/10.1371/journal.pone.0114070

Earl, D. A., \& vonHoldt, B. M. (2012). STRUCTURE HARVESTER: A website and program for visualizing STRUCTURE output and implementing the Evanno method. Conservation Genetics Resources, 4(2), 359-361. https://doi.org/10.1007/s12686-011-9548-7

Elmer, K. R. (2016). Genomic tools for new insights to variation, adaptation, and evolution in the salmonid fishes: A perspective for charr. Hydrobiologia, 783(1), 191-208. https://doi.org/10.1007/s1075 0-10015-12614-10755

Eloranta, A. P., Siwertsson, A., Knudsen, R., \& Amundsen, P. A. (2011). Dietary plasticity of Arctic charr (Salvelinus alpinus) facilitates coexistence with competitively superior European whitefish (Coregonus lavaretus). Ecology of Freshwater Fish, 20(4), 558-568. https://doi. org/10.1111/j.1600-0633.2011.00504.x

Evanno, G., Regnaut, S., \& Goudet, J. (2005). Detecting the number of clusters of individuals using the software STRUCTURE: A simulation study. Molecular Ecology, 14(8), 2611-2620. https://doi. org/10.1111/j.1365-294X.2005.02553.x

Excoffier, L., Laval, G., \& Schneider, S. (2005). Arlequin (version 3.0): An integrated software package for population genetics data analysis. Evolutionary Bioinformatics, 1, 47-50. https://doi.org/10.1177/11769 3430500100003

Folch, J., Lees, M., \& Sloane-Stanley, G. (1957). A simple method for the isolation and purification of total lipids from animal tissues. Journal of Biological Chemistry, 226(1), 497-509.

Fussmann, G. F., Loreau, M., \& Abrams, P. A. (2007). Eco-evolutionary dynamics of communities and ecosystems. Functional Ecology, 21(3), 465-477. https://doi.org/10.1111/j.1365-2435.2007.01275.x

Goudet, J. (1995). FSTAT (version 1.2): A computer program to calculate F-statistics. Journal of Heredity, 86(6), 485-486.

Goudet, J., Raymond, M., de Meeüs, T., \& Rousset, F. (1996). Testing differentiation in diploid populations. Genetics, 144(4), 1933.

Guzzo, M. M., Blanchfield, P. J., \& Rennie, M. D. (2017). Behavioral responses to annual temperature variation alter the dominant energy 
pathway, growth, and condition of a cold-water predator. Proceedings of the National Academy of Sciences, 114(37), 9912. https://doi. org/10.1073/pnas.1702584114

Hammer, Ø., Harper, D., \& Ryan, P. (2001). Past: Paleontological statistics software package for education and data analysis. Palaeontologia Electronica, 4, 1-9.

Handelsman, C. A., Broder, E. D., Dalton, C. M., Ruell, E. W., Myrick, C. A., Reznick, D. N., \& Ghalambor, C. K. (2013). Predator-induced phenotypic plasticity in metabolism and rate of growth: Rapid adaptation to a novel environment. Integrative and Comparative Biology, 53(6), 975-988. https://doi.org/10.1093/icb/ict057

Happel, A., Jonas, J. L., McKenna, P., Rinchard, J., He, J. X., \& Czesny, S. J. (2017). Spatial variability of lake trout diets in lakes Huron and Michigan revealed by stomach content and fatty acid profiles. Canadian Journal of Fisheries and Aquatic Sciences, 75(1), 95-105. https://doi.org/10.1139/cjfas-2016-0202

Happel, A., Stratton, L., Pattridge, R., Rinchard, J., \& Czesny, S. (2016). Fatty-acid profiles of juvenile lake trout reflect experimental diets consisting of natural prey. Freshwater Biology, 61(9), 1466-1476. https://doi.org/10.1111/fwb.12786

Harris, L. N., Chavarie, L., Bajno, R., Howland, K. L., Wiley, S. H., Tonn, W. M., \& Taylor, E. B. (2015). Evolution and origin of sympatric shallow-water morphotypes of Lake Trout, Salvelinus namaycush, in Canada's Great Bear Lake. Heredity, 114(1), 94-106. https://doi. org/10.1038/hdy.2014.74

Harris, L. N., Howland, K. L., Kowalchuk, M. W., Bajno, R., Lindsay, M. M., \& Taylor, E. B. (2013). Microsatellite and mtDNA analysis of lake trout, Salvelinus namaycush, from Great Bear Lake, Northwest Territories: Impacts of historical and contemporary evolutionary forces on Arctic ecosystems. Ecology and Evolution, 3(1), 145-161. https://doi.org/10.1002/ece3.439

Hendry, A. P. (2009). Ecological speciation! Or the lack thereof? This perspective is based on the author's J.C. Stevenson Memorial Lecture delivered at the Canadian Conference for Fisheries Research in Halifax, Nova Scotia, January 2008. Canadian Journal of Fisheries and Aquatic Sciences, 66(8), 1383-1398. https://doi.org/10.1139/F09-074

Hendry, A. P. (2016). Key questions on the role of phenotypic plasticity in eco-evolutionary dynamics. Journal of Heredity, 107, 25-41. https:// doi.org/10.1093/jhered/esv060

Hendry, A. P., Bolnick, D. I, Berner, D., \& Peichel, C. L. (2009a). Along the speciation continuum in sticklebacks. Journal of Fish Biology, 75(8), 2000-2036. https://doi.org/10.1111/j.1095-8649.2009.02419.x

Hendry, A. P., Nosil, P., \& Rieseberg, L. H. (2007). The speed of ecological speciation. Functional Ecology, 21(3), 455-464. https://doi. org/10.1111/j.1365-2435.2007.01240.x

Hoffmann, J. M. (2017). Investigating trophic ecology and dietary niche overlap among morphs of Lake Trout in Lake Superior (MS thesis). University of Waterloo.

Hosmer, D. W. Jr, Lemeshow, S., \& Sturdivant, R. X. (2000). Model-building strategies and methods for logistic regression (3rd ed., pp. 89-151). Applied Logistic Regression.

Howell, K. L., Pond, D. W., Billett, D. S., \& Tyler, P. A. (2003). Feeding ecology of deep-sea seastars (Echinodermata: Asteroidea): A fatty-acid biomarker approach. Marine Ecology Progress Series, 255, 193-206. https://doi.org/10.3354/meps255193

Howland, K. L., Gallagher, C., Boguski, D., Chavarie, L., Reist, J., Rosenburg, B., \& Wiley, S. (2013). Variation in morphology, life history and ecology of cisco in Great Bear Lake, Northwest Territories, Canada. (2013/106). Sci. Advis. Sec. Res. Doc.

Hubisz, M. J., Falush, D., Stephens, M., \& Pritchard, J. K. (2009). Inferring weak population structure with the assistance of sample group information. Molecular Ecology Resources, 9(5), 1322-1332. https://doi. org/10.1111/j.1755-0998.2009.02591.x

Husson, F., Josse, J., Le, S., \& Mazet, J. (2012). FactoMineR: Multivariate exploratory data analysis and data mining with $R$. R package version 1.18 .
Iverson, S. J. (2009). Tracing aquatic food webs using fatty acids: From qualitative indicators to quantitative determination. In M. Kainz, M. Brett, M. Arts (Eds.), Lipids in aquatic ecosystems (pp. 281-308). New York, NY: Springer. https://doi.org/10.1007/978-0-387-89366-2_12

Iverson, S. J., Field, C., Bowen, W. D., \& Blanchard, W. (2004). Quantitative fatty acid signature analysis: A new method of estimating predator diets. Ecological Monographs, 74, 211-235. https://doi. org/10.1890/02-4105

Jakobsson, M., \& Rosenberg, N. A. (2007). CLUMPP: A cluster matching and permutation program for dealing with label switching and multimodality in analysis of population structure. Bioinformatics, 23(14), 1801-1806. https://doi.org/10.1093/bioinformatics/btm233

Johnson, L. (1975). Distribution of fish species in Great Bear Lake, Northwest Territories, with reference to zooplankton, benthic invertebrates, and environmental conditions. Journal of the Fisheries Research Board of Canada, 32, 1989-2004. https://doi.org/10.1139/ f75-235

Jombart, T. (2008). adegenet: A R package for the multivariate analysis of genetic markers. Bioinformatics, 24(11), 1403-1405. https://doi. org/10.1093/bioinformatics/btn129

Jombart, T., Devillard, S., \& Balloux, F. (2010). Discriminant analysis of principal components: A new method for the analysis of genetically structured populations. BMC Genetics, 11(1), 94. https://doi. org/10.1186/1471-2156-11-94

Jonsson, B., \& Jonsson, N. (2001). Polymorphism and speciation in Arctic charr. Journal of Fish Biology, 58(3), 605-638. https://doi. org/10.1111/j.1095-8649.2001.tb00518.x

Kahilainen, K., Malinen, T., Tuomaala, A., \& Lehtonen, H. (2004). Diel and seasonal habitat and food segregation of three sympatric Coregonus lavaretus forms in a subarctic lake. Journal of Fish Biology, 64(2), 418434. https://doi.org/10.1111/j.0022-1112.2004.00307.x

Kalinowski, S. T. (2005). hp-rare 1.0: A computer program for performing rarefaction on measures of allelic richness. Molecular Ecology Notes, 5(1), 187-189

Kassen, R. (2002). The experimental evolution of specialists, generalists, and the maintenance of diversity. Journal of Evolutionary Biology, 15(2), 173-190. https://doi.org/10.1046/j.1420-9101.2002.00377.x

Kattner, G., Hagen, W., Graeve, M., \& Albers, C. (1998). Exceptional lipids and fatty acids in the pteropod Clione limacina (Gastropoda) from both polar oceans. Marine Chemistry, 61(3), 219-228. https://doi. org/10.1016/S0304-4203(98)00013-9

Kavanagh, A. S., Cronin, M. A., Walton, M., \& Rogan, E. (2010). Diet of the harbour seal (Phoca vitulina vitulina) in the west and south-west of Ireland. Journal of the Marine Biological Association of the United Kingdom, 90(08), 1517-1527.

Keva, O., Tang, P., Käkelä, R., Hayden, B., Taipale, S. J., Harrod, C., \& Kahilainen, K. K. (2019). Seasonal changes in European whitefish muscle and invertebrate prey fatty acid composition in a subarctic lake. Freshwater Biology, 64(11), 1908-1920. https://doi.org/10.1111/ fwb.13381

King, J. R., \& Jackson, D. A. (1999). Variable selection in large environmental data sets using principal components analysis. Environmetrics, 10(1), 67-77. https://doi.org/10.1002/(SICI)1099-095X(19990 1/02)10:1<67:AID-ENV336>3.0.CO;2-0

Knudsen, R., Primicerio, R., Amundsen, P.-A., \& Klemetsen, A. (2010). Temporal stability of individual feeding specialization may promote speciation. Journal of Animal Ecology, 79(1), 161-168. https://doi. org/10.1111/j.1365-2656.2009.01625.x

Kohda, M., Shibata, J.-Y., Awata, S., Gomagano, D., Takeyama, T., Hori, M., \& Heg, D. (2008). Niche differentiation depends on body size in a cichlid fish: A model system of a community structured according to size regularities. Journal of Animal Ecology, 77(5), 859-868. https:// doi.org/10.1111/j.1365-2656.2008.01414.x

Kristjánsson, B. K., Skúlason, S., \& Noakes, D. L. G. (2002). Morphological segregation of Icelandic threespine stickleback (Gasterosteus 
aculeatus L). Biological Journal of the Linnean Society, 76(2), 247-257. https://doi.org/10.1046/j.1095-8312.2002.00063.x

Lamichhaney, S., Fan, G., Widemo, F., Gunnarsson, U., Thalmann, D. S., Hoeppner, M. P., Kerje, S., Gustafson, U., Shi, C., Zhang, H. E., Chen, W., Liang, X., Huang, L., Wang, J., Liang, E., Wu, Q., Lee, S.-Y., Xu, X., Höglund, J., ... Andersson, L. (2016). Structural genomic changes underlie alternative reproductive strategies in the ruff (Philomachus pugnax). Nature Genetics, 48(1), 84-88. https://doi.org/10.1038/ ng.3430

Loseto, L. L., Stern, G. A., Connelly, T. L., Deibel, D., Gemmill, B., Prokopowicz, A., Fortier, L., \& Ferguson, S. H. (2009). Summer diet of beluga whales inferred by fatty acid analysis of the eastern Beaufort Sea food web. Journal of Experimental Marine Biology and Ecology, 374(1), 12-18. https://doi.org/10.1016/j. jembe.2009.03.015

MacDonald, D., Levy, D., Czarnecki, A., Low, G., \& Richea, N. (2004). State of the aquatic knowledge of Great Bear Lake watershed. Report to Indian and Northern Affairs Canada. Water Resources Division, MacDonald Environmental Sciences, Nanaimo, British Columbia.

Maderbacher, M., Bauer, C., Herler, J., Postl, L., Makasa, L., \& Sturmbauer, C. (2008). Assessment of traditional versus geometric morphometrics for discriminating populations of the Tropheus moorii species complex (Teleostei: Cichlidae), a Lake Tanganyika model for allopatric speciation. Journal of Zoological Systematics and Evolutionary Research, 46(2), 153-161.

Manor, M. L., Weber, G. M., Cleveland, B. M., \& Kenney, P. B. (2014). Effects of feeding level and sexual maturation on fatty acid composition of energy stores in diploid and triploid rainbow trout (Oncorhynchus mykiss). Aquaculture, 418-419, 17-25. https://doi. org/10.1016/j.aquaculture.2013.09.023

Marin, K., Coon, A., Carson, R., Debes, P. V., \& Fraser, D. J. (2016). Striking phenotypic variation yet low genetic differentiation in sympatric lake trout (Salvelinus namaycush). PLoS One, 11(9), e0162325. https://doi. org/10.1371/journal.pone.0162325

McCune, B., \& Mefford, M. J. (2011). PC-ORD v. 6.255 beta. MjM Software. Gleneden Beach, Lincoln.

McGill, B. J., Enquist, B. J., Weiher, E., \& Westoby, M. (2006). Rebuilding community ecology from functional traits. Trends in Ecology \& Evolution, 21(4), 178-185. https://doi.org/10.1016/j. tree.2006.02.002

McMeans, B. C., McCann, K. S., Humphries, M., Rooney, N., \& Fisk, A. T. (2015). Food web structure in temporally-forced ecosystems. Trends in Ecology \& Evolution, 30(11), 662-672. https://doi.org/10.1016/j. tree.2015.09.001

Morrison, W. R., \& Smith, L. M. (1964). Preparation of fatty acid methyl esters and dimethylacetals from lipids with boron fluoride-methanol. Journal of Lipid Research, 5(4), 600-608.

Muir, A. M., Bronte, C. R., Zimmerman, M. S., Quinlan, H. R., Glase, J. D., \& Krueger, C. C. (2014). Ecomorphological diversity of Lake Charr Salvelinus namaycush at Isle Royale, Lake Superior. Transactions of the American Fisheries Society, 143(4), 972-987.

Muir, A. M., Vecsei, P., \& Krueger, C. C. (2012). A perspective on perspectives: A method toward reducing variation in digital shape analysis. Transactions of the American Fisheries Society, 141(4), 1161-1170. https://doi.org/10.1080/00028487.2012.685823

Nagel, L., \& Schluter, D. (1998). Body size, natural selection, and speciation in sticklebacks. Evolution, 52(1), 209-218. https://doi. org/10.1111/j.1558-5646.1998.tb05154.x

Narum, S. R. (2006). Beyond Bonferroni: Less conservative analyses for conservation genetics. Conservation Genetics, 7(5), 783-787. https:// doi.org/10.1007/s10592-005-9056-y

Nonaka, E., Svanbäck, R., Thibert-Plante, X., Englund, G., \& Brännström, Å. (2015). Mechanisms by which phenotypic plasticity affects adaptive divergence and ecological speciation. American Naturalist, 186(5), 126-143. https://doi.org/10.1086/683231
Nosil, P., Harmon, L. J., \& Seehausen, O. (2009). Ecological explanations for (incomplete) speciation. Trends in Ecology \& Evolution, 24(3), 145156. https://doi.org/10.1016/j.tree.2008.10.011

Parent, C. E., Agashe, D., \& Bolnick, D. I. (2014). Intraspecific competition reduces niche width in experimental populations. Ecology and Evolution, 4(20), 3978-3990. https://doi.org/10.1002/ece3.1254

Pfennig, D. W., \& Pfennig, K. S. (2012). Evolution's wedge: Competition and the origins of diversity. Univ of California Press.

Pfennig, D. W., Wund, M. A., Snell-Rood, E. C., Cruickshank, T., Schlichting, C. D., \& Moczek, A. P. (2010). Phenotypic plasticity's impacts on diversification and speciation. Trends in Ecology \& Evolution, 25(8), 459-467. https://doi.org/10.1016/j.tree.2010.05.006

Piché, J., Iverson, S. J., Parrish, F. A., \& Dollar, R. (2010). Characterization of forage fish and invertebrates in the northwestern Hawaiian Islands using fatty acid signatures: Species and ecological groups. Marine Ecology Progress Series, 418, 1-15. https://doi.org/10.3354/ meps08814

Pielou, E. C. (2008). After the ice age: The return of life to glaciated North America. University of Chicago Press.

Pires, M. M., Guimarães, P. R., Araújo, M. S., Giaretta, A. A., Costa, J. C. L., \& dos Reis, S. F. (2011). The nested assembly of individual-resource networks. Journal of Animal Ecology, 80(4), 896-903. https:// doi.org/10.1111/j.1365-2656.2011.01818.x

Præbel, K., Knudsen, R., Siwertsson, A., Karhunen, M., Kahilainen, K. K., Ovaskainen, O., \& Amundsen, P. A. (2013). Ecological speciation in postglacial European whitefish: Rapid adaptive radiations into the littoral, pelagic, and profundal lake habitats. Ecology and Evolution, 3(15), 4970-4986.

Pritchard, J. K., Stephens, M., \& Donnelly, P. (2000). Inference of population structure using multilocus genotype data. Genetics, 155(2), 945-959.

Quevedo, M., Svanbäck, R., \& Eklöv, P. (2009). Intrapopulation niche partitioning in a generalist predator limits food web connectivity. Ecology, 90(8), 2263-2274. https://doi.org/10.1890/07-1580.1

Quinn, T. J. II, \& Deriso, R. B. (1999). Quantitative fish dynamics. Oxford University Press.

Richardson, J. L., Urban, M. C., Bolnick, D. I., \& Skelly, D. K. (2014). Microgeographic adaptation and the spatial scale of evolution. Trends in Ecology \& Evolution, 29(3), 165-176. https://doi.org/10.1016/j. tree.2014.01.002

Roesti, M., Kueng, B., Moser, D., \& Berner, D. (2015). The genomics of ecological vicariance in threespine stickleback fish. Nature Communications, 6, 8767. https://doi.org/10.1038/ncomms9767

Ronconi, R., Koopman, H. N., McKinstry, C., Wong, S., \& Westgate, A. J. (2010). Inter-annual variability in diet of non-breeding pelagic seabirds Puffinus spp. at migratory staging areas: Evidence from stable isotopes and fatty acids. Marine Ecology Progress Series, 419, 267-282. https://doi.org/10.3354/meps08860

Rosenberg, N. A. (2004). DISTRUCT: A program for the graphical display of population structure. Molecular Ecology Notes, 4(1), 137-138. https://doi.org/10.1046/j.1471-8286.2003.00566.x

Roughgarden, J. (1972). Evolution of niche width. American Naturalist, 106(952), 683-718. https://doi.org/10.1086/282807

Rousset, F. (2008). genepop'007: A complete re-implementation of the genepop software for Windows and Linux. Molecular Ecology Resources, 8(1), 103-106. https://doi.org/10.1111/j.1471-8286.2007.01931.x

Rueger, T., Gardiner, N. M., \& Jones, G. P. (2016). Size matters: Male and female mate choice leads to size-assortative pairing in a coral reef cardinalfish. Behavioral Ecology, 27(6), 1585-1591. https://doi. org/10.1093/beheco/arw082

Ruess, L., \& Müller-Navarra, D. C. (2019). Essential biomolecules in food webs. Frontiers in Ecology and Evolution, 7(269), https://doi. org/10.3389/fevo.2019.00269

Ryman, N., \& Palm, S. (2006). POWSIM: A computer program for assessing statistical power when testing for genetic 
differentiation. Molecular Ecology Notes, 6(3), 600-602. https://doi. org/10.1111/j.1471-8286.2006.01378.x

Scharnweber, K., Strandberg, U., Karlsson, K., \& Eklöv, P. (2016). Decrease of population divergence in Eurasian perch (Perca fluviatilis) in browning waters: Role of fatty acids and foraging efficiency. PLoS One, 11(9), e0162470. https://doi.org/10.1371/journ al.pone.0162470

Schluter, D. (2000). The ecology of adaptive radiation. Oxford University Press.

Servedio, M. R., Doorn, G. S. V., Kopp, M., Frame, A. M., \& Nosil, P. (2011). Magic traits in speciation: 'magic' but not rare? Trends in Ecology \& Evolution, 26(8), 389-397. https://doi.org/10.1016/j. tree.2011.04.005

Sharpe, D. M., Räsänen, K., Berner, D., \& Hendry, A. P. (2008). Genetic and environmental contributions to the morphology of lake and stream stickleback: Implications for gene flow and reproductive isolation. Evolutionary Ecology Research, 10(6), 849-866.

Skúlason, S., Parsons, K. J., Svanbäck, R., Räsänen, K., Ferguson, M. M., Adams, C. E., Amundsen, P.-A., Bartels, P., Bean, C. W., Boughman, J. W., Englund, G., Guðbrandsson, J., Hooker, O. E., Hudson, A. G., Kahilainen, K. K., Knudsen, R., Kristjánsson, B. K., Leblanc, C.-.-L., Jónsson, Z., ... Snorrason, S. S. (2019). A way forward with eco evo devo: An extended theory of resource polymorphism with postglacial fishes as model systems. Biological Reviews, 94(5), 1786-1808. https://doi.org/10.1111/brv.12534

Skulason, S., \& Smith, T. B. (1995). Resource polymorphisms in vertebrates. Trends in Ecology \& Evolution, 10, 366-370. https://doi. org/10.1016/S0169-5347(00)89135-1

Skúlason, S., Snorrason, S. S., \& Jonsson, B. (1999). Sympatric morphs, populations and speciation in freshwater fish with emphasis on arctic charr. In A. E. Magurran, \& R. M. May (Eds.), Evolution of biological diversity (p. 329). Oxford University Press.

Smith, J., Baumgartner, L., Suthers, I., \& Taylor, M. (2011). Generalist niche, specialist strategy: The diet of an Australian percichthyid. Journal of Fish Biology, 78(4), 1183-1199. https://doi. org/10.1111/j.1095-8649.2011.02926.x

Snorrason, S. S., \& Skúlason, S. (2004). Adaptive speciation in northern freshwater fishes. Adaptive speciation (pp. 210-228). Cambridge University Press.

Stowasser, G., Pierce, G. J., Moffat, C. F., Collins, M. A., \& Forsythe, J. W. (2006). Experimental study on the effect of diet on fatty acid and stable isotope profiles of the squid Lolliguncula brevis. Journal of Experimental Marine Biology and Ecology, 333(1), 97-114. https://doi. $\operatorname{org} / 10.1016 /$ j.jembe.2005.12.008

Sušnik, S., Knizhin, I., Snoj, A., \& Weiss, S. (2006). Genetic and morphological characterization of a Lake Ohrid endemic, Salmo (Acantholingua) ohridanus with a comparison to sympatric Salmo trutta. Journal of Fish Biology, 68(A), 2-23. https://doi. org/10.1111/j.0022-1112.2006.00902.x

Svanbäck, R., \& Bolnick, D. I. (2005). Intraspecific competition affects the strength of individual specialization: An optimal diet theory method. Evolutionary Ecology Research, 7(7), 993-1012.

Svanbäck, R., \& Persson, L. (2004). Individual diet specialization, niche width and population dynamics: Implications for trophic polymorphisms. Journal of Animal Ecology, 73(5), 973-982. https://doi. org/10.1111/j.0021-8790.2004.00868.x

Svanbäck, R., Pineda-Krch, M., \& Doebeli, M. (2009). Fluctuating population dynamics promotes the evolution of phenotypic plasticity. The American Naturalist, 174(2), 176-189. https://doi. org/10.1086/600112

Svanbäck, R., Quevedo, M., Olsson, J., \& Eklöv, P. (2015). Individuals in food webs: The relationships between trophic position, omnivory and among-individual diet variation. Oecologia, 178(1), 103-114. https://doi.org/10.1007/s00442-014-3203-4
Svanbäck, R., \& Schluter, D. (2012). Niche specialization influences adaptive phenotypic plasticity in the threespine stickleback. The American Naturalist, 180(1), 50-59. https://doi.org/10.1086/666000

Team, R. C (2015). R: A language and environment for statistical computing. Vienna, Austria.

Team, R. C (2017). R: A language and environment for statistical computing. R Foundation for Statistical Computing.

Tucker, S., Bowen, W. D., \& Iverson, S. J. (2008). Convergence of diet estimates derived from fatty acids and stable isotopes within individual grey seals. Marine Ecology Progress Series, 354, 267. https://doi. org/10.3354/meps07263

Turcotte, M. M., Reznick, D. N., \& Hare, J. D. (2011). The impact of rapid evolution on population dynamics in the wild: Experimental test of eco-evolutionary dynamics. Ecology Letters, 14(11), 1084-1092. https://doi.org/10.1111/j.1461-0248.2011.01676.x

Van Kleunen, M., \& Fischer, M. (2005). Constraints on the evolution of adaptive phenotypic plasticity in plants. New Phytologist, 166(1), 4960. https://doi.org/10.1111/j.1469-8137.2004.01296.x

Van Oosterhout, C., Hutchinson, W. F., Wills, D. P., \& Shipley, P. (2004). MICRO-CHECKER: Software for identifying and correcting genotyping errors in microsatellite data. Molecular Ecology Notes, 4(3), 535538. https://doi.org/10.1111/j.1471-8286.2004.00684.x

Vander Zanden, M. J., Shuter, B. J., Lester, N. P., \& Rasmussen, J. B. (2000). Within-and among-population variation in the trophic position of a pelagic predator, lake trout (Salvelinus namaycush). Canadian Journal of Fisheries and Aquatic Sciences, 57(4), 725-731.

Violle, C., Enquist, B. J., McGill, B. J., Jiang, L., Albert, C. H., Hulshof, C., Jung, V., \& Messier, J. (2012). The return of the variance: Intraspecific variability in community ecology. Trends in Ecology \& Evolution, 27(4), 244-252. https://doi.org/10.1016/j.tree.2011.11.014

Virtue, P., Mayzaud, P., Albessard, E., \& Nichols, P. (2000). Use of fatty acids as dietary indicators in northern krill, Meganyctiphanes norvegica, from northeastern Atlantic, Kattegat, and Mediterranean waters. Canadian Journal of Fisheries and Aquatic Sciences, 57(S3), 104-114.

Vonlanthen, P., Roy, D., Hudson, A. G., LargiadÈR, C. R., Bittner, D., \& Seehausen, O. (2009). Divergence along a steep ecological gradient in lake whitefish (Coregonus sp.). Journal of Evolutionary Biology, 22(3), 498-514. https://doi.org/10.1111/j.1420-9101.2008.01670.x

Wainwright, P. C., \& Price, S. A. (2016). The impact of organismal innovation on functional and ecological diversification. Integrative and Comparative Biology, 56(3), 479-488. https://doi.org/10.1093/icb/ icw081

Webb, P. W. (1984). Body form, locomotion and foraging in aquatic vertebrates. American Zoologist, 24, 107-120. https://doi.org/10.1093/ $\mathrm{icb} / 24.1 .107$

Weir, B. S., \& Cockerham, C. C. (1984). Estimating F-statistics for the analysis of population structure. Evolution, 1358-1370.

Werner, E. E., \& Gilliam, J. F. (1984). The ontogenetic niche and species interactions in size-structured populations. Annual Review of Ecology and Systematics, 15, 393-425. https://doi.org/10.1146/annur ev.es.15.110184.002141

West-Eberhard, M. J. (2003). Developmental plasticity and evolution. Oxford University Press.

Zar, J. (2010). Biostatistical analysis. Pearson education. Pearson Education Inc.

Zelditch, M. L., Swiderski, D. L., \& Sheets, H. D. (2012). Geometric morphometrics for biologists: A primer. Academic Press.

Zhao, T., Villéger, S., Lek, S., \& Cucherousset, J. (2014). High intraspecific variability in the functional niche of a predator is associated with ontogenetic shift and individual specialization. Ecology and Evolution, 4(24), 4649. https://doi.org/10.1002/ece3.1260

Zimmerman, M. S., Krueger, C. C., \& Eshenroder, R. L. (2006). Phenotypic diversity of lake trout in Great Slave Lake: Differences in morphology, 
buoyancy, and habitat depth. Transactions of the American Fisheries Society, 135, 1056-1067. https://doi.org/10.1577/T05-237.1

Zimmerman, M. S., Krueger, C. C., \& Eshenroder, R. L. (2007).

Morphological and ecological differences between shallow- and deep-water lake trout in Lake Mistassini, Quebec. Journal of Great Lakes Research, 33, 156-169.10.3394/0380-1330(2007)33[156:MA EDBS]2.0.CO;2

\section{SUPPORTING INFORMATION}

Additional supporting information may be found online in the Supporting Information section.
How to cite this article: Chavarie L, Howland KL, Harris LN, et al. Among-individual diet variation within a lake trout ecotype: Lack of stability of niche use. Ecol Evol.

2021;11:1457-1475. https://doi.org/10.1002/ece3.7158 